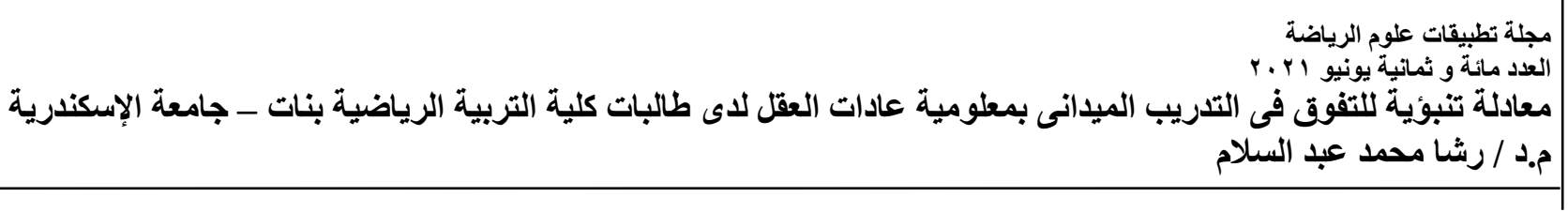

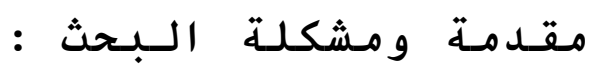

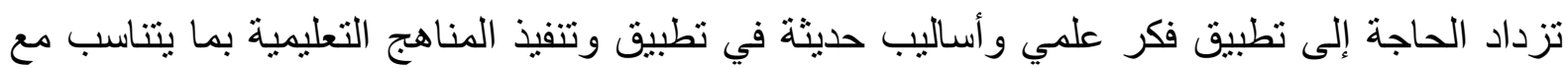

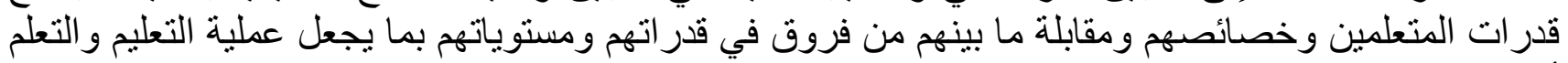

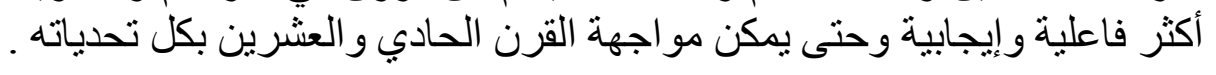

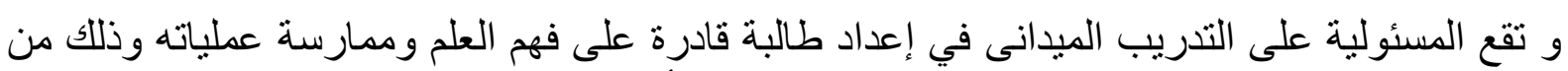

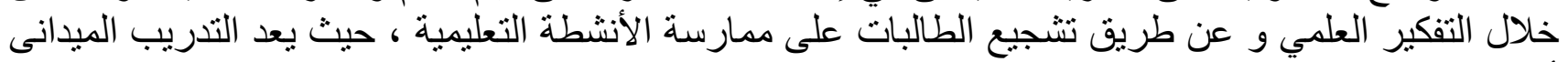

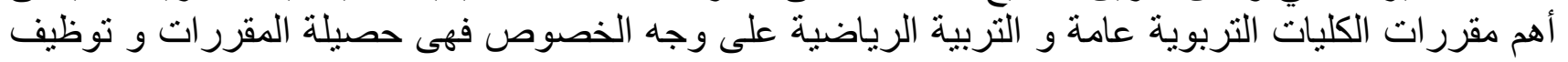

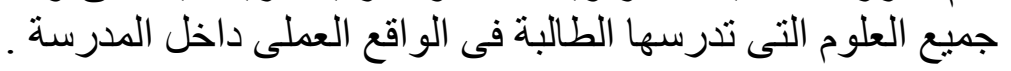

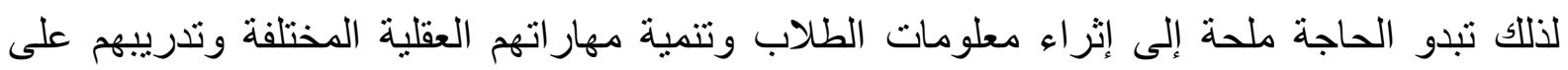

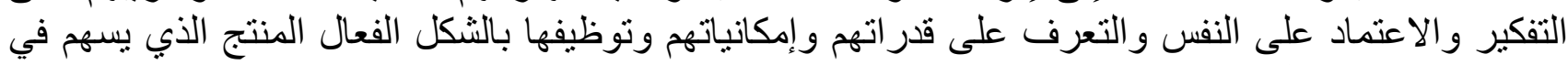

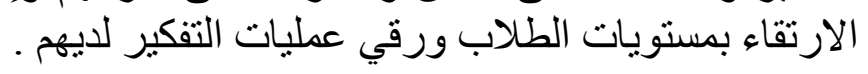

\section{(I THR:}

و لابد من تنوع طرق و أساليب التعلم لأن الطلاب لا يتعلمون بطريقة واحدة ويوجد بينهم اختلافات متعددة سواء

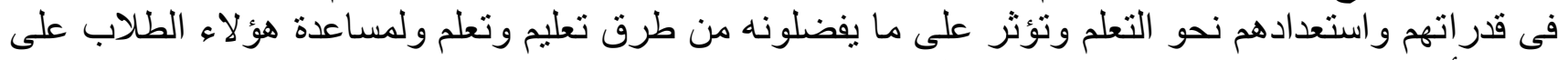

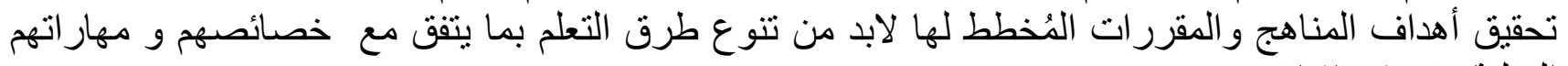

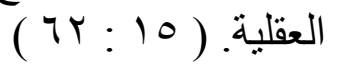

و تللك المهار ات العقلية يتم تتميتها عن طريق عادات العقل والتى يستطيعون من خلالها رؤية العلاقات المختلفة

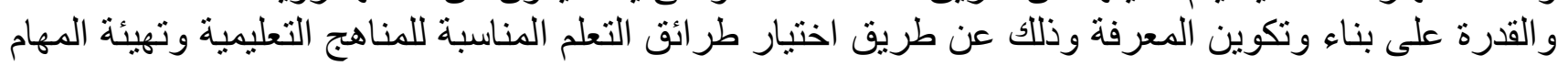
التعليمية المرتبطة بتنمية هذه العادات. (

و تتمية عادات العقل يساعد في تنظيم المخزون المعرفي للمتعلم وإدارة أفكاره بفاعلية حيث تعتبر القاعدة

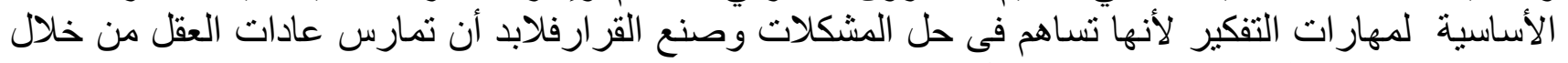

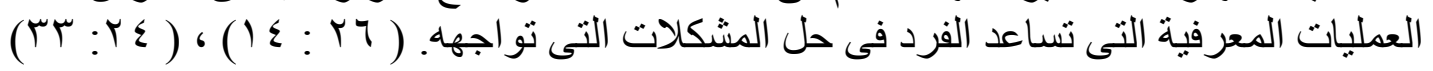

لذلك فانه ينبغي أن تكون عادات العقل محورا للتعلم وان يتضمن منهج التعليم تدريسا صريحا وواضحا

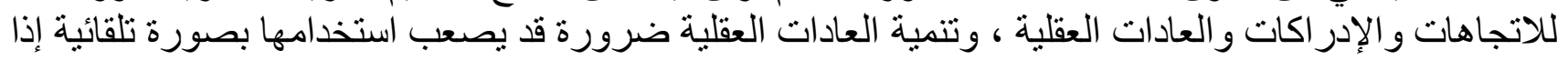

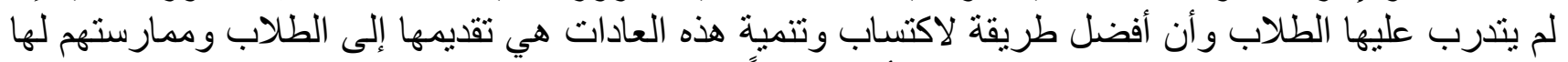

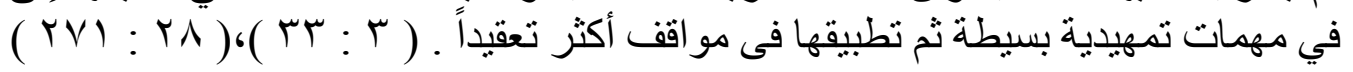
ويرى الكثير من متخصصي التدريب الميدانى في المجتمع الدولي انه ينبغي تنمية عادات العقل من خلال: تفسير

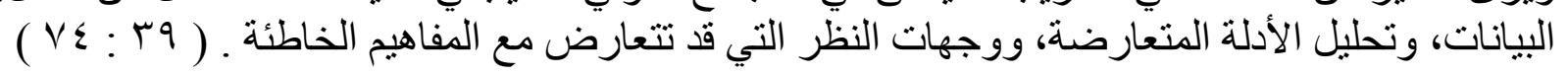
و عادات العقل عبارة عن مجموعة من السلوكيات الذكية الواعية التي ينتهجها الفرد باستمر ار دون جهد أو عناء

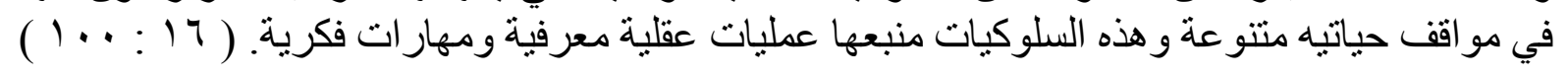
و هى مجمو عة من المهار ات المرتبط ادائها بالعقل وتساعد الفرد على السلوك الذى يؤدى غلى أفضل الاستجابات

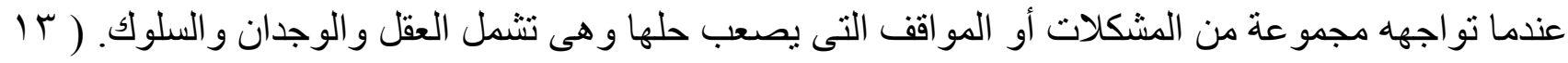

$(r \cdot r$ : 


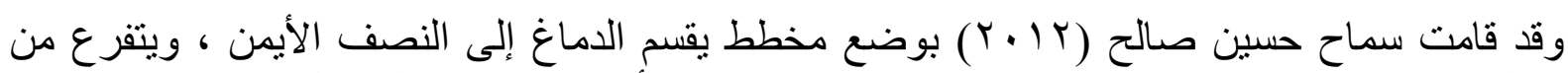

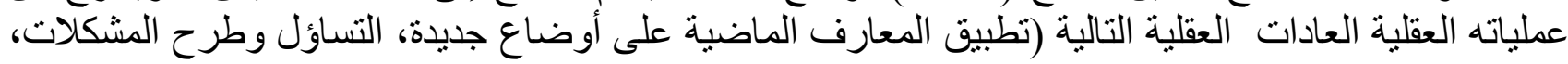

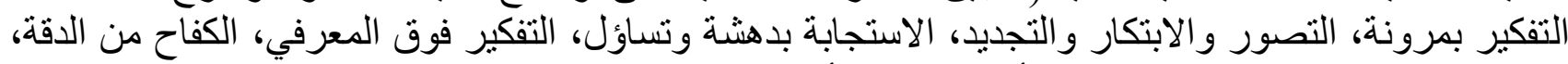

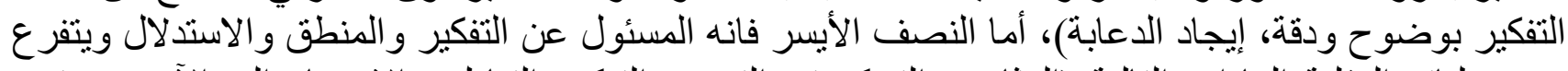

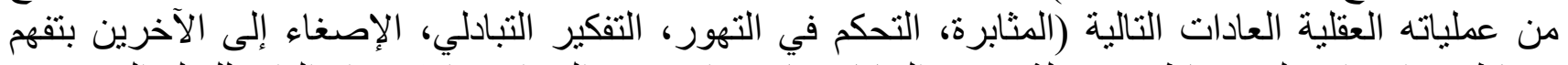

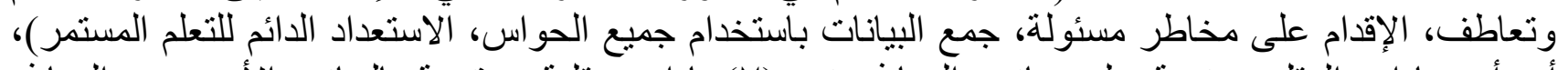

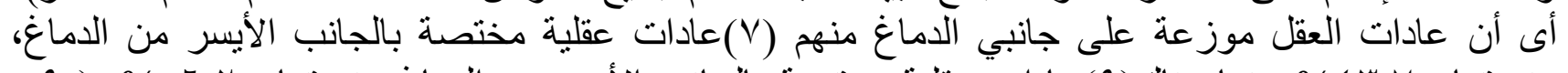

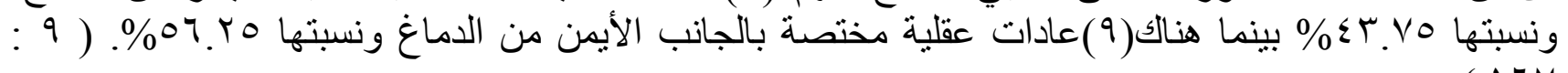

و تتمثل الاهمية التربوية لعادات العقل فى تشجع الطلاب على التعلم وتجعلهم أكثر نشاطا فى إدارة تعلمهم، تعلمهم

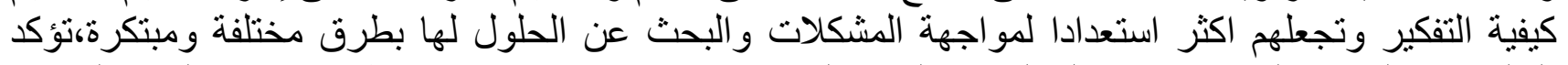

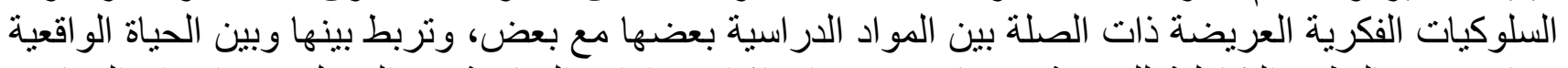

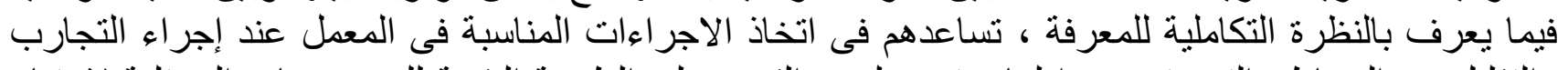

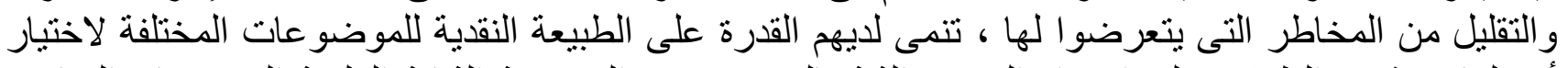

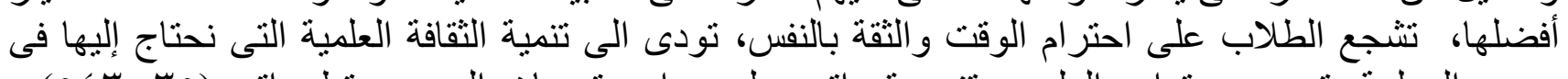

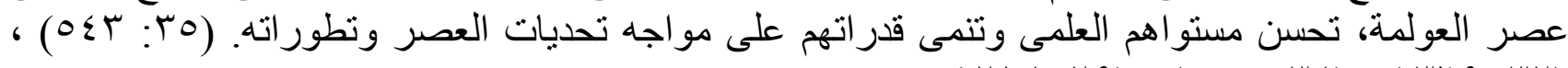

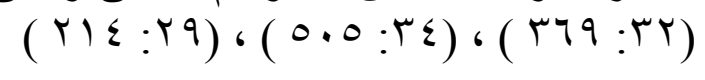

و تكوين كل عادة عقلية يتطلب أن تسير ضمن مر احل كالتالي التفكير : وفيها يفكر الشخص في الثيء ويركز

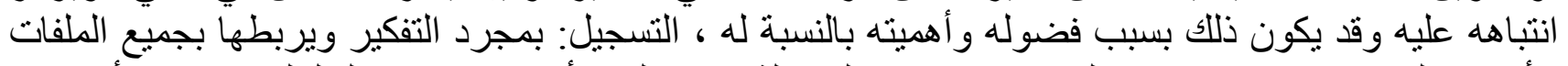

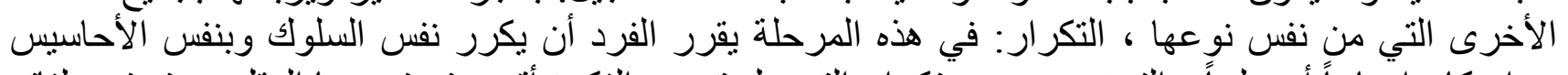

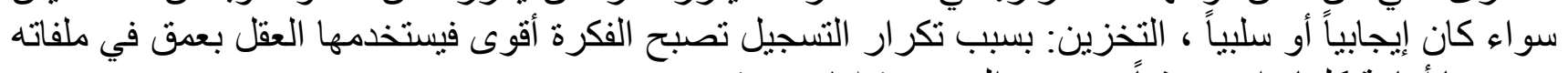

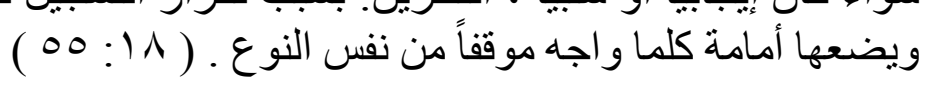

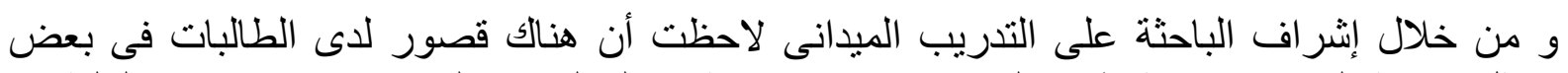

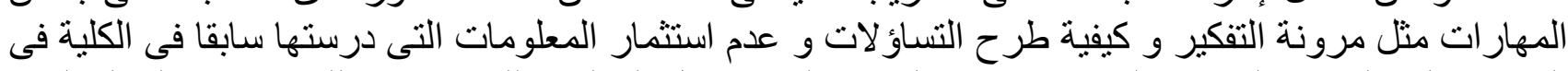

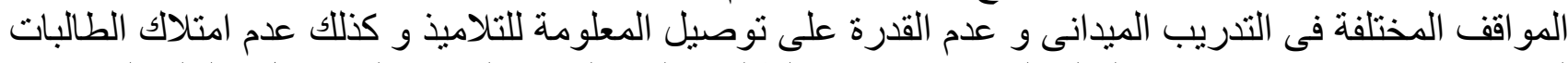

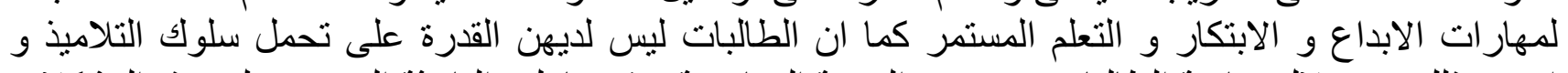

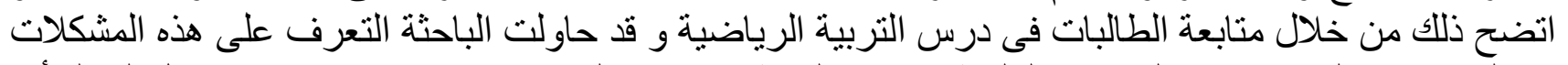

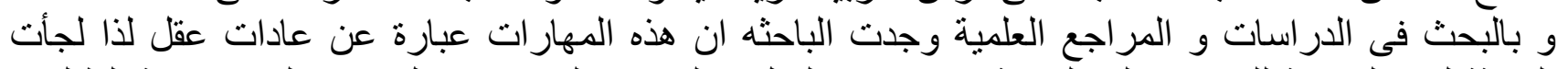

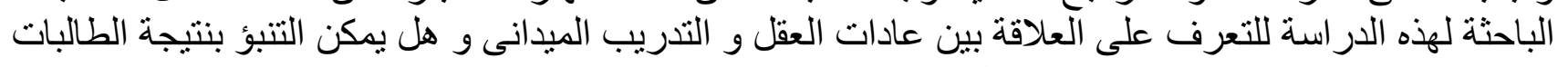

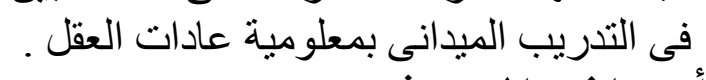

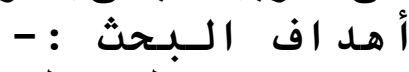
يهدف البحث إلى التحث : التوصل الى معادلة تنبؤية للتفوق فى التدريب الميدانى بمعلوميـة عـادات العقل و ذلك من خلال : ا ـ التعرف على عادات العقل المساهمة فى التفوق فى التذريب الميدانى .

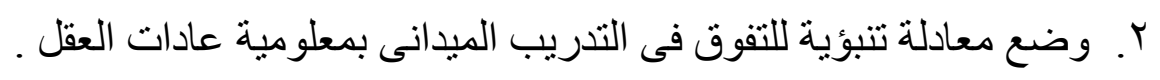

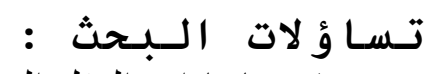

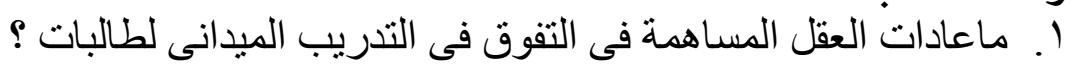

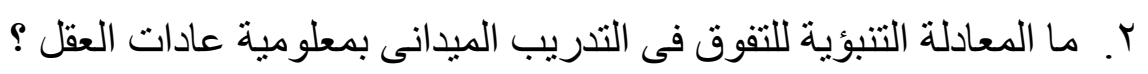

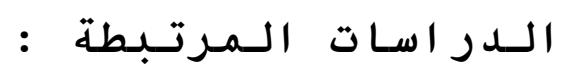

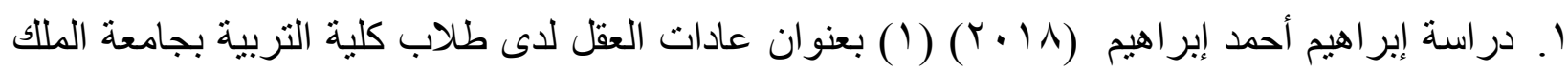

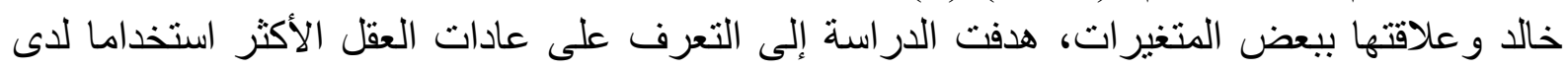




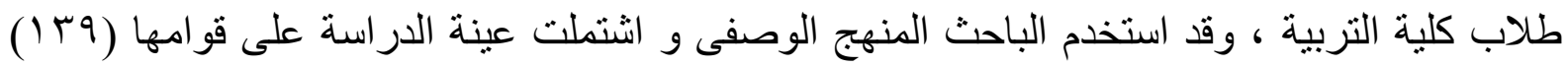
طالب و كانت أهم النتائج أن أكثر عادات العقل استخداما لدى طلاب كلية التربية عادة المثابرة و التفكير

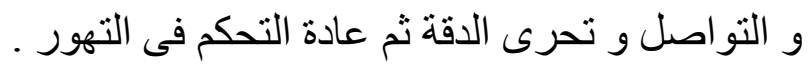

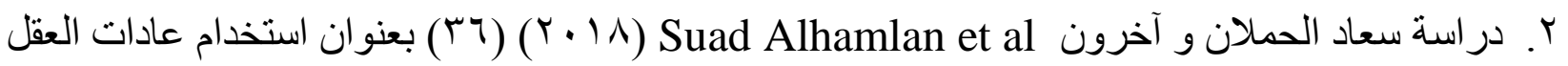
لتحسين التفكير لدى الطلاب ، هدفت الدر اسة إلى التعرف على أثر أثت استخدام عادات العقل لتحسين التفكير

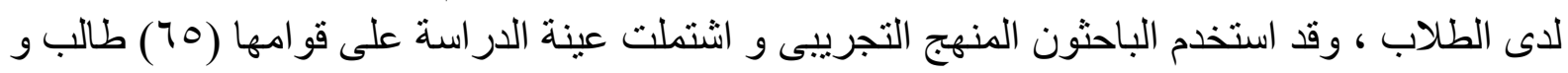

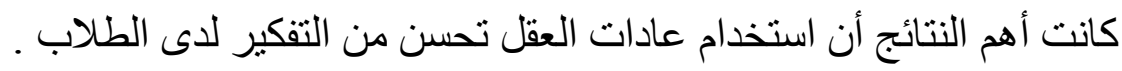

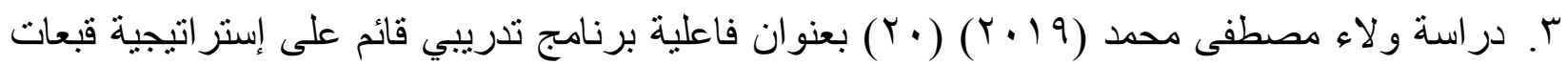

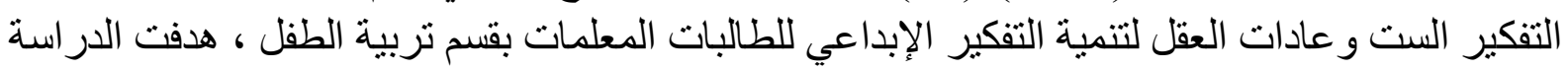
إلى تتمية مهار ات التفكير الإبداعي الأساسية المتمثلة في (الطلاقة ـ الأصالة - المرونة التئة) باستخدام

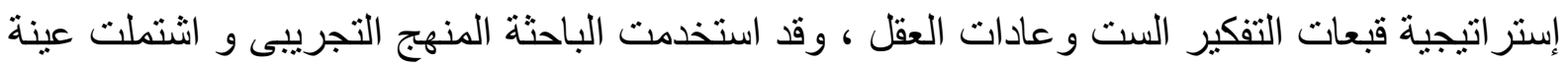

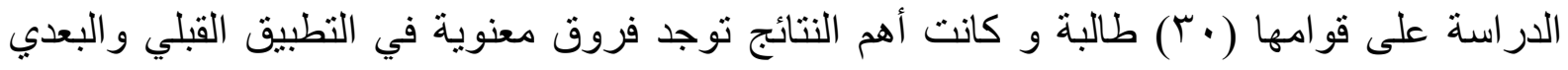

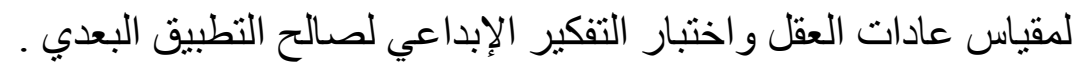

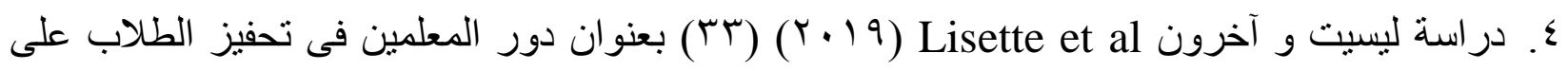

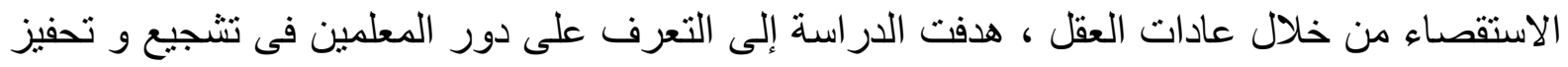

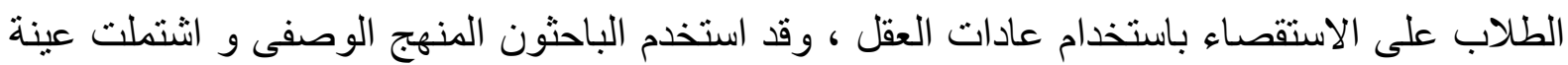

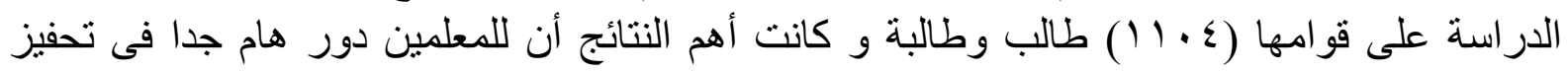
الطلاب على الاستقصاء و البحث باستخدام عادات العقل .

\section{أوجه الإستفادة من الاراسات المرتبطة :}

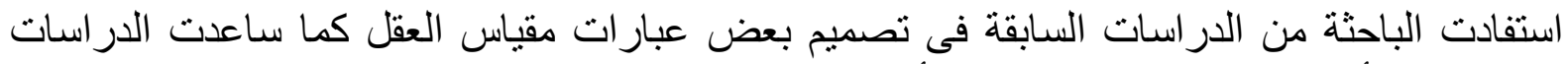

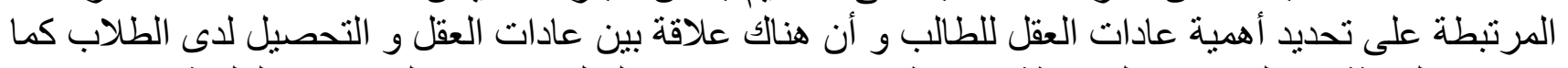

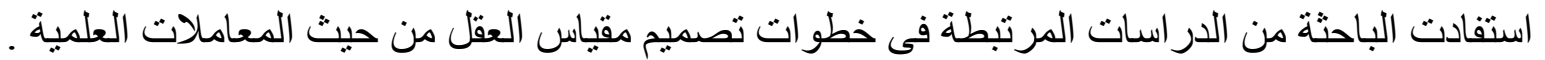

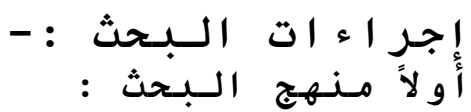

$$
\begin{aligned}
& \text { إستخدمت الباحثة المنهج الوصفى بالأسلوب المسحى. }
\end{aligned}
$$

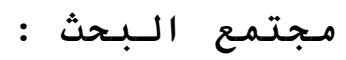

طالبات الفرقة الر ابعة شعبة تعليم بكلية التربية الرياضية بنات جامعة الإسكندرية و قد تم أخذ درجاتهن

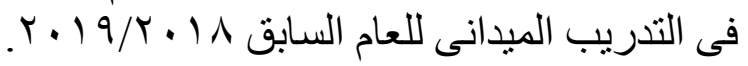

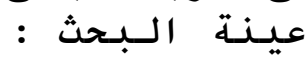

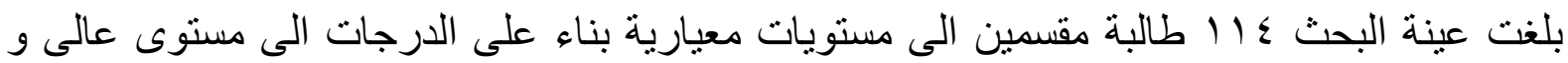

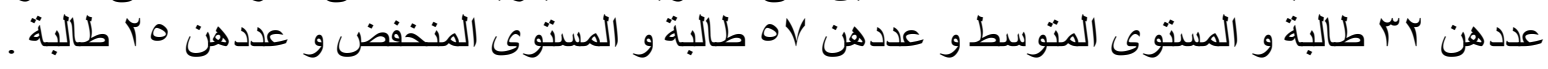


جدول (1 ) التوصيف العددى لمجتمع وعينة البحث

\begin{tabular}{|c|c|c|c|c|c|c|c|c|}
\hline \multicolumn{2}{|c|}{ العينة الاستطلاعية } & \multicolumn{2}{|c|}{ العينة الأساسية } & \multicolumn{2}{|c|}{ عينة البحثة } & \multicolumn{2}{|c|}{ المجتمع } & \multirow{2}{*}{ المستويات } \\
\hline النسبة\%\% & العدد & النسبة\%\% & العدد & النسبة\%\% & العدد & النسبة\%\% & العدد & \\
\hline$r \wedge . \wedge q$ & 14 & 11.11 & $r r$ & $91 . \wedge \varepsilon$ & $\leqslant 0$ & rI.Ar & $\varepsilon 9$ & العالى \\
\hline 17.11 & 11 & Ar.Ar & ov & $90 . V V$ & 71 & $\leq 4.1$ & vi & المتوسط \\
\hline$r 1 . \wedge \Lambda$ & V & $V \Lambda .1 T$ & ro & $9 \varepsilon .14$ & $r r$ & Yr..A & $r \leqslant$ & المنذفض \\
\hline$r$ r.rs & $r$ & V^. Tr & $11 \leq$ & 95.17 & $1 \leqslant 0$ & $1 \ldots$ & $10 \leqslant$ & المجموع \\
\hline
\end{tabular}

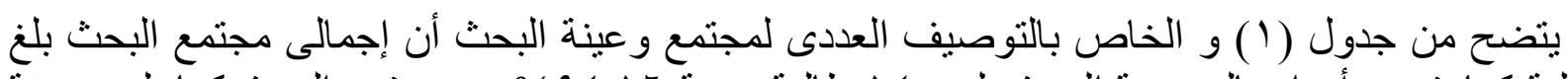

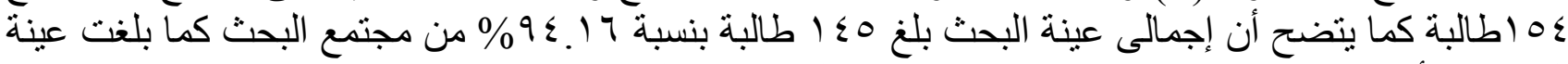

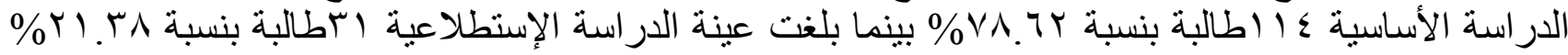

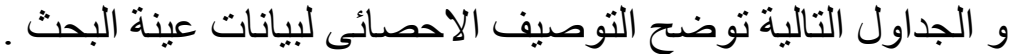

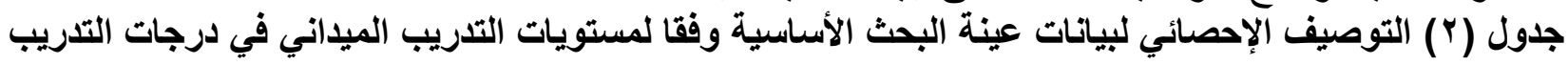

\begin{tabular}{|c|c|c|c|c|c|c|c|}
\hline \multicolumn{5}{|c|}{ الالالات الإحصائية للتوصيف } & \multirow[b]{2}{*}{ العدد ن } & \multirow[b]{2}{*}{ المستوى } & \multirow[b]{2}{*}{ المحاور } \\
\hline 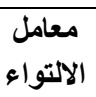 & التقلطح & الالتعراف & الوسيط & الحسابي & & & \\
\hline .011 & $\because 0$. & $0 . r v$ & IAT & $1 \wedge r .74$ & $r r$ & مستوى عالى & \multirow{4}{*}{ درجات التدريب الميدانى } \\
\hline$\because \cdot v=$ & $1.1 \%=$ & $0 . Y \leq$ & 171 & $17 . .57$ & ov & مستوى متوسط & \\
\hline $1.0 \leqslant-$ & r.17 & Y0.9 & $1 \leqslant T$ & Irr.*A & ro & مستوى منذفض & \\
\hline $1.1 \leqslant-$ & $r . \wedge r$ & 91.97 & 174 & $19 . .57$ & $11 \varepsilon$ & العينة الكلية & \\
\hline
\end{tabular}

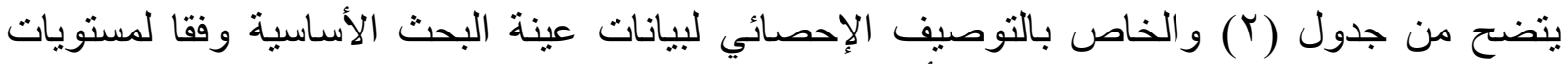

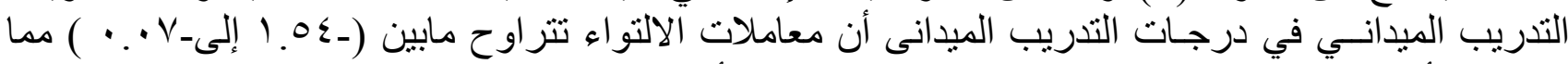

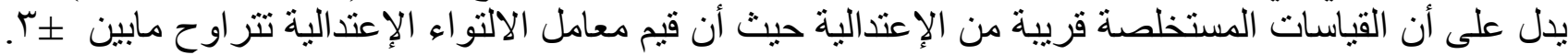

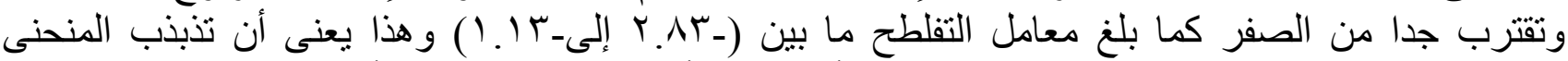
الاعتدالى يعتبر مقبو لا وفى المتوسط وليس متذبذبا لأعلى و لا لأسفل مما يؤكد تجانس أفراد عينة البحت البح الكلية . 
جدول (r) التوصيف الإحصائي لبيانات عينة البحث الاساسية وفقا لمستويات التدريب الميدانى في عادات ومجموع مقياس عادات العقل

\begin{tabular}{|c|c|c|c|c|c|c|c|}
\hline \multicolumn{5}{|c|}{ اللالات الإحصائية للتوصيف } & \multirow[b]{2}{*}{ العدد ن ن } & \multirow[b]{2}{*}{ المستوى } & \multirow[b]{2}{*}{ العادات } \\
\hline الالتواء & التفطامح & الالتحراف & الوسيط & المسابي & & & \\
\hline - & .0. & $1.0 Y$ & Ir & $11 . \leqslant 1$ & rr & مستوى عالى & \multirow{4}{*}{ التحكم بالتهور } \\
\hline. .17 &.$r q$ & $1.0 \mathrm{~V}$ & Ir & 11.7. & ov & مستوى متوسط & \\
\hline $1 . \leqslant \%$ & $\Gamma . \wedge \wedge$ & 1.19 & 11 & $11 . r$. & ro & مستوى منخفض & \\
\hline . & 1.54 & 1.74 & Ir & 11.57 & $11 \leqslant$ & العينة الكلية & \\
\hline .00 &.$r^{9}$ & 1.90 & $1 \varepsilon$ & 15.91 & rr & مستوى عالى & \multirow{4}{*}{ الاصغاء بتفهم } \\
\hline..$\mu 1$ & $r .99$ &. .97 & $1 \varepsilon$ & $1 \leqslant . \leqslant 7$ & ov & مستوى متوسط & \\
\hline 1.01. & r.ry & $1 . r v$ & $1 \varepsilon$ & 14.99 & ro & مستوى منخفض & \\
\hline. .VY & 9.11 & $1.1 \mathrm{~V}$ & $1 \varepsilon$ & 15.19 & 115 & العينة الكلية & \\
\hline$\cdot . \varepsilon_{-}$ & $\because .0 \mathrm{~V}$ & 1.11 & 11 & 11.40 & rr & مستوى عالى & \multirow{4}{*}{ التفكير بمرونة } \\
\hline$\cdot r^{r}$ & $1 . r$ & 1.10 & 11 & 11.95 & ov & مستوى متوسط & \\
\hline $1 . \leqslant 0$ & $\varepsilon .91$ & $1 . \leqslant V$ & 11 & $11 . \ldots$ & ro & مستوى منخفض & \\
\hline$\cdot . \leqslant \Lambda_{-}$ & $r . v 1$ & $1 . r$. & 11 & 11.99 & $11 \varepsilon$ & العينة الكلية & \\
\hline $1.01=$ & 1.9 & 1.rr & 10 & $1 \varepsilon .19$ & rr & مستوى عالى & \multirow{4}{*}{ التفكير ما وراء } \\
\hline $.9 Y_{-}$ &.$\leqslant 0_{-}$ & $1.0 Y$ & 10 & 14.89 & ov & مستوى متوسط & \\
\hline$\cdot . \top \Lambda_{-}$ & $1 . \varepsilon Y_{-}$ & $\varepsilon .11$ & 14 & $11 . \varepsilon$. & ro & مستوى منذفض & \\
\hline 1.0. & r.AT & $r .00$ & 10 & Ir.rA & $11 \leq$ & العينة الكلية & \\
\hline $1 . \leqslant 9-$ & Y.AT & $1 . \leqslant \varepsilon$ & 10 & $14.9 \leq$ & rr & مستوى عالى & \multirow{4}{*}{ الكفاح من أجل الدقة } \\
\hline 1.0. & $1 . r r$ & 1.74 & 14 & Ir.rT & ov & مستوى متوسط & \\
\hline$\cdot . \leqslant V_{-}$ & $1.01=$ & r.0 & Ir & $1 \cdot . r Y$ & ro & مستوى منخفض & \\
\hline $1.7 \Lambda_{-}$ & Y.QY & r.OT & ir & IY.As & $11 \varepsilon$ & العينة الكلية & \\
\hline .09 &.$\leqslant 9-$ & 1.47 & 1. & Q.YY & rr & مستوى عالى & \multirow{4}{*}{ التساؤل وطرح } \\
\hline$\cdot V Y_{-}$ & $.0 \%-$ & 1.11 & 1. & 9.7 & ov & مستوى متوسط & \\
\hline.$V Y_{-}$ &. $.1 Y$ & 1.11 & 1. & $9.7 \leq$ & ro & مستوى منخفض & \\
\hline $.21-$ & . Tr- & $1 . M$ & 1. & 9.0. & $11 \varepsilon$ & العينة الكلية & \\
\hline $1 . \cdot 1$. & .rtr- & $1 . r \varepsilon$ & Ir & $11.1 \%$ & rr & مستوى عالى & \multirow{4}{*}{ الماضية في مواقفت } \\
\hline .19 & $1.1 \leqslant-$ & $1 . r Y$ & 1. & $1 . .0 \leq$ & ov & مستوى متوسط & \\
\hline$. .21-$ & 1.rV- & Y.VT & 9 & $\Lambda .17$ & ro & مستوى منخفض & \\
\hline $1 . \leqslant Y-$ & $r . \cdot V$ & $r . r$ & 1. & $1 . .11$ & $11 \leqslant$ & العينة الكلية & \\
\hline $1.59=$ & .04 & 1.29 & 10 & $\mid r . \wedge 1$ & rr & مستوى عالى & \multirow{4}{*}{ بوضيوح ودقة التفيل } \\
\hline$\cdot r O_{-}$ & $1 . \leqslant Y_{-}$ & r.Ir & 14 & $1 Y .20$ & ov & مستوى متوسط & \\
\hline$\because \cdots$ & $.91-$ & T.YT & 1. & 9.7 & ro & مستوى منخفض & \\
\hline 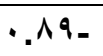 & $\cdot . r \mu$ & r.VV & 14 & IY.rT & $11 \leq$ & العينة الكلية & \\
\hline
\end{tabular}


تابع جدول (ب) التوصيف الإحصائي لبيانات عينة البحث الاساسية وفقا لمستويات التدريب الميدانى في عادات ومجموع مقياس عادات العقل

\begin{tabular}{|c|c|c|c|c|c|c|c|}
\hline \multicolumn{5}{|c|}{ الدالات الإحصائية للتوصيف } & \multirow[b]{2}{*}{ العدد ن } & \multirow[b]{2}{*}{ المستوى } & \multirow[b]{2}{*}{ العادات } \\
\hline الالتواء & التقلطح & الالحعرى & الوسيط & المستبي & & & \\
\hline $1.59-$ &. $.0 r$ & 1.89 & 10 & $\mid r . \wedge 1$ & rr & مستوى عالى & \multirow{4}{*}{ باستخدام البيانات } \\
\hline. YOH & $1 . \leqslant Y=$ & r.Ir & ir & IY.Vo & ov & مستوى متوسط & \\
\hline$\because \cdots$ & $.91-$ & r.YT & 1. & 9.7. & ro & مستوى منخفض & \\
\hline$. . \wedge 9-$ & $\because r r$ & Y.VV & ir & IY.ru & $11 \varepsilon$ & العينة الكلية & \\
\hline $1 . \leqslant 9-$ & $.9 r$ & 1.04 & ir & 11.99 & rr & مستوى عالى & \multirow{4}{*}{ والابداع والتخيل } \\
\hline$\cdot . V \cdot-$ &.$\Delta Y_{-}$ & 1.01 & 1. & $1 . .70$ & OV & مستوى متوسط & \\
\hline. .47 & $1.41=$ & r.91 & 1. & N.rr & ro & مستوى منخفض & \\
\hline $1 . r \Lambda_{-}$ & 1.0 & r.17 & 1. & $1 . .57$ & $11 \varepsilon$ & العينة الكلية & \\
\hline $1 . \leqslant \leqslant-$ & $1 . \leqslant 9$ & 1.71 & 10 & $14.9 \leq$ & rr & مستوى عالى & \multirow{4}{*}{ ودذشابة بدقة } \\
\hline$\cdot . \vee \Lambda_{-}$ & $.1-$ & 1.89 & ir & IT.YT & ov & مستوى متوسط & \\
\hline$. .1-$ & $1 . \leqslant \leqslant-$ & r.7. & ir & $1 \cdot . r r$ & ro & مستوى منخفض & \\
\hline $1 . \leqslant \Lambda_{-}$ & $1 . \wedge r$ & r.TY & ir & Ir.Vq & $11 \varepsilon$ & العينة الكلية & \\
\hline$\because \cdot V$ & $. .0 T-$ & 1.10 & $\mathrm{~V}$ & $V . r r$ & $r r$ & مستوى عالى & \multirow{4}{*}{ الإقام على المخاطرلة } \\
\hline .10 & 1.94 & $1 . \cdots$ & $\mathrm{V}$ & $V .0 \leq$ & $\Delta V$ & مستوى متوسط & \\
\hline$\because .0 r$ & $.0 \leqslant-$ & .911 & $\mathrm{v}$ & V.rA & ro & مستوى منخفض & \\
\hline .1 &.$\because \Lambda_{-}$ & 1.0 & $\mathrm{v}$ & $V . r \leq$ & $11 \varepsilon$ & العينة الكلية & \\
\hline . rTs & .70 & $1 . r \varepsilon$ & ir & $1 T .14$ & $r r$ & مستوى عالى & \multirow{4}{*}{ إيجاد الدعابة } \\
\hline$\cdot Y \leqslant-$ & $.0 \leq-$ & 1.0. & 14 & $1 r . \wedge 9$ & ov & مستوى متوسط & \\
\hline .04 & $\cdot \wedge \cdot-$ & Y.YO & Ir & $1 \cdot . \Lambda$. & ro & مستوى منخفض & \\
\hline $.90_{-}$ & $1.1 \%$ & $1 . \wedge \mathrm{V}$ & ir & Ir.o. & $11 \varepsilon$ & العينة الكلية & \\
\hline$\because .7$ & $\because \varepsilon V-$ & 1.70 & 9 & 9.41 & $r r$ & مستوى عالى & \multirow{4}{*}{ التفكير التبادلى } \\
\hline$\because .11$ & 1.04 & 1.87 & 9 & $1 . \cdots$ & ov & مستوى متوسط & \\
\hline. .71 & $1 . \cdot \leq-$ & 1.21 & 9 & $9.7 \varepsilon$ & ro & مستوى منخفض & \\
\hline$\because .1 \leqslant$ & $.94=$ & $1.0 Y$ & 9 & $9 . v r$ & $11 \varepsilon$ & العينة الكلية & \\
\hline$\cdot . V Y_{-}$ & .09 & $1.2 V$ & 11 & $1 . .77$ & $r r$ & مستوى عالى & \multirow{4}{*}{ التعلم المستمر } \\
\hline$\because .0-$ & $1.7 \cdot-$ & $1 . \leqslant r$ & 1. & $1 \cdot . r r$ & $\Delta V$ & مستوى متوسط & \\
\hline$. . \$ 1-$ & 1.00 & r.IV & 9 & 1.17 & ro & مستوى منخفض & \\
\hline$\therefore \wedge \theta_{-}$ & $.0 r$ & $1 . \wedge \wedge$ & 1. & 9.90 & $11 \leq$ & العينة الكلية & \\
\hline $1 . .1-$ & $\cdot r_{-}$ & $1 . r \varepsilon$ & Ir & $11.1 \%$ & $r r$ & مستوى عالى & \multirow{4}{*}{ اللجمقوع الكلى } \\
\hline$. .19-$ & $1.1 \leqslant-$ & $1 . r r$ & 1. & $1 . .0 \leq$ & $\Delta V$ & مستوى متوسط & \\
\hline$. . \$ 1-$ & $1 . r V=$ & r.VY & 9 & 1.17 & ro & مستوى منخفض & \\
\hline $1 . \leqslant Y-$ & $r . \cdot V$ & $r . r r$ & 1. & $1 . .11$ & $11 \leq$ & العينة الكلية & \\
\hline. $\mathrm{V} \theta_{-}$ &.$r \wedge$ & 11.97 & 195 & $111.9 \leq$ & rr & مستوى عالى & \multirow{4}{*}{ المجموع الكلى } \\
\hline ـ ـ & $.7 V=$ & $1 \leq .49$ & 110 & $110 . .0$ & ov & مستوى متوسط & \\
\hline$. .71-$ & $.9 \leq-$ & $r . \wedge q$ & IVT & $10 V .07$ & ro & مستوى منخفض & \\
\hline $1.11-$ & Y.\&1 & $r Y . \xi V$ & IAr.o & $11 \cdot .11$ & $11 \varepsilon$ & العينة الكلية & \\
\hline
\end{tabular}

يتضح دن جدول (r) و الخاص بالتوصيف الإحصائي لبيانات عينة البحث الأساسية وفقا لمستويات

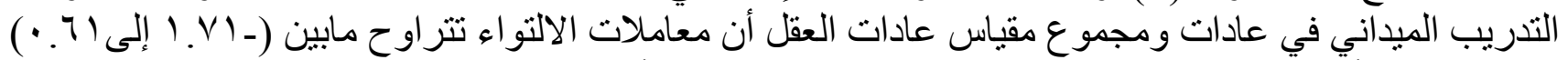
مما يدل على أن القياسات المستخلصة قريبة من الإعتدالية حيث أن قيم معامل الالتواء الإعتدالية تتراوحات الته مابين 


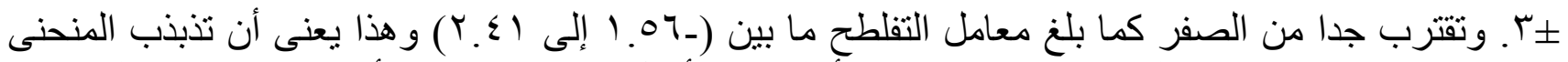

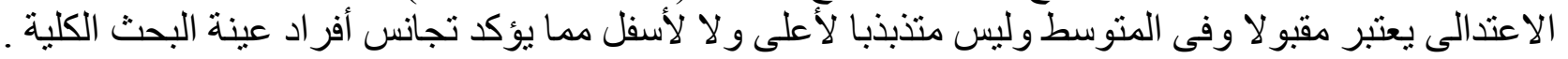

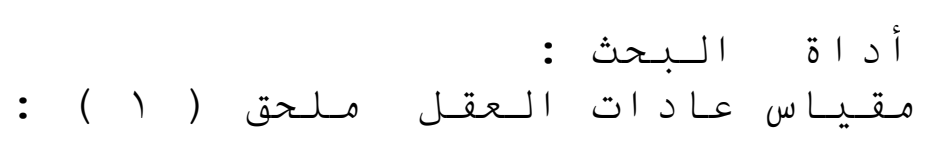

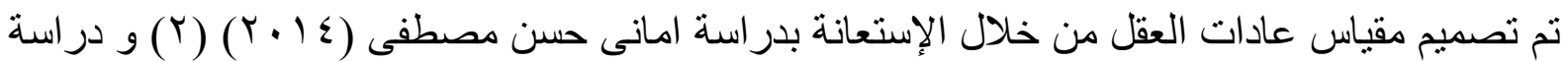

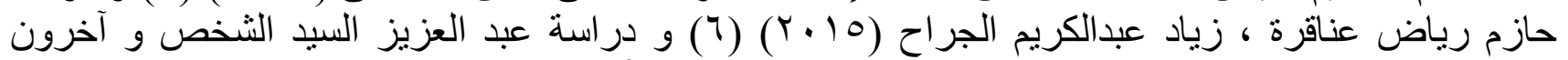

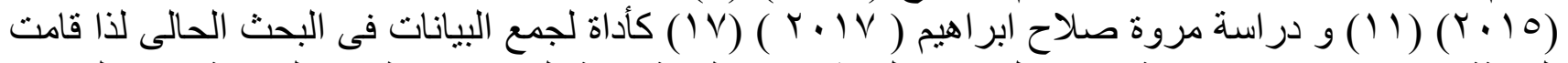

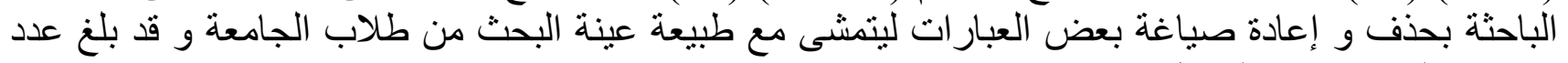

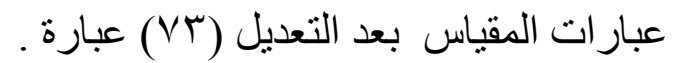

$$
\begin{aligned}
& \text { وصف الـمقـيـاسم : }
\end{aligned}
$$

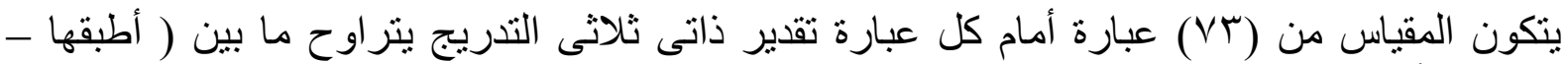

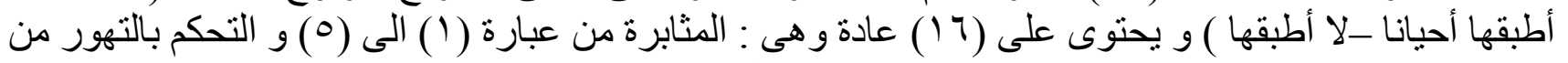

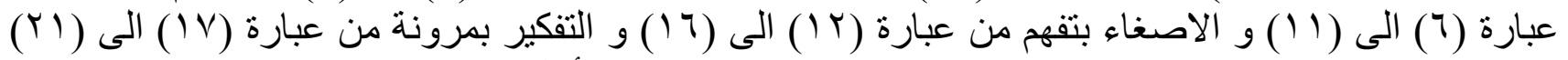

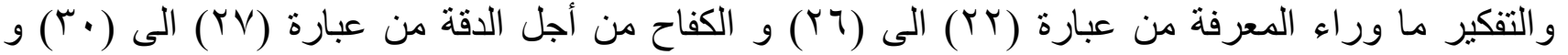

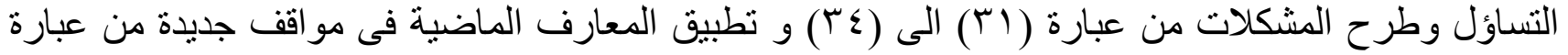

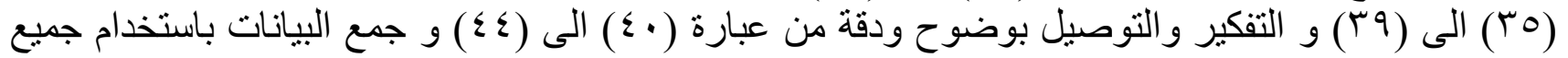

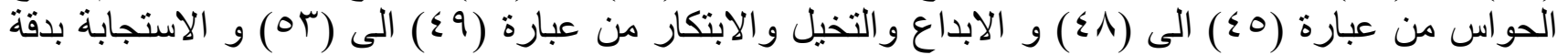

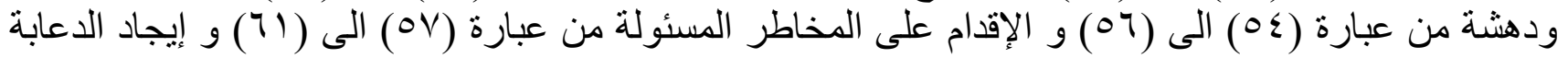

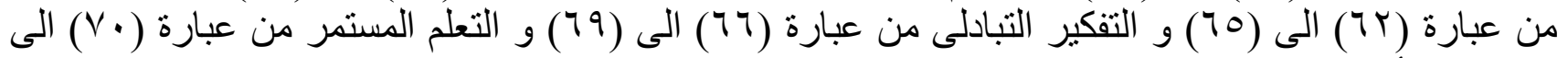

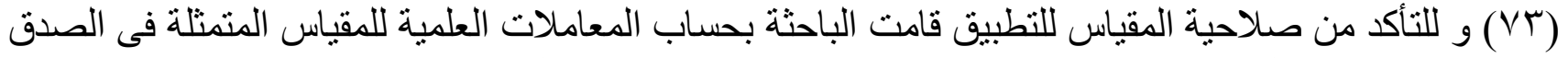

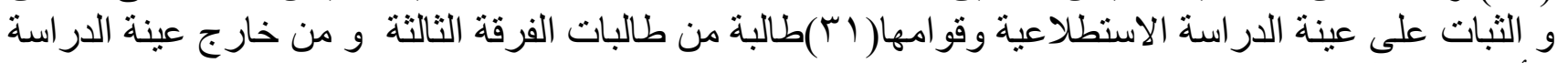

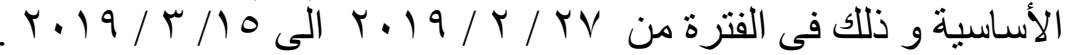

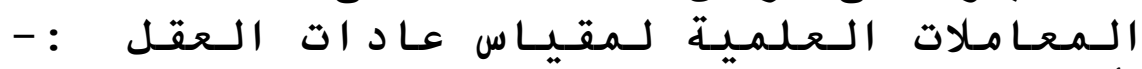
أولا الصدق :

تم حساب الصدق باستخدام طريقة الاتساق الداخلي عن طريق حساب معاملات الارثباط بين درجة

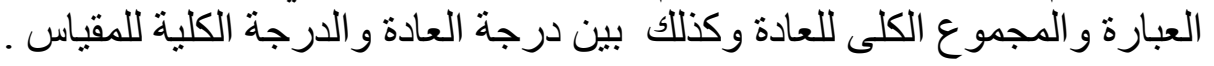


جدول ( ) معامل الاتساق الداخلى (معامل ارتباط درجة العبارة بالمجموع الكلى للعادة التى تنتمى اليها) لعبارات

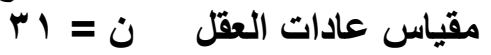

\begin{tabular}{|c|c|c|c|}
\hline معامل الاتساق & العبارات & P & العادة \\
\hline$* * ., 7 \leqslant 0$ & أستمر في تطبيق الحصة حتى تصبح حصة مكتملة. & 1 & \multirow{5}{*}{ المثابرة } \\
\hline${ }^{* *} \cdot .74 \Lambda$ & أحدد ما أريد معرفتّة وما أحتاج له قبل تطبيق الحصة. & 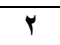 & \\
\hline$* * . V \leqslant r$ & أحافظ على التفكير الإيجابى الذى يتعلق بتطبيق الحصة. & $r$ & \\
\hline **..VIr & استطيع تطيق الحصة مهما زادت عليها الأراء السلبية من قبل الأخرين . & $\varepsilon$ & \\
\hline **. $.4 \%$ & أحلد خطوات تطبيق الحصة وتحليل المشكلة التى تواجهنى بوضوح. & • & \\
\hline$* * .779$ & لا لا أرغب فى الوصول الى النتائج السريعة. & 7 & \multirow{6}{*}{ بالتهور } \\
\hline$* * . \mathrm{V} 0\}$ & أحترم الحلول البديلة مـا دامت تخذم الحصة ويسهل تطبيقها & $\mathrm{v}$ & \\
\hline **. .949 & أتتأنى لبناء خطة عمل قبل البذء فى تنفيذ الحصة. & $\Lambda$ & \\
\hline$\star * . .700$ & أتفهر خصائص التلاميذ أثناء تطبيق الحصة . & 9 & \\
\hline **..v०r & أفكر فى البائل التى من الممكن تطيقها فى الحصة. & 1. & \\
\hline${ }^{* *} \cdot . V 19$ & أتجنب التقييم الفورى وأتأنى عند تقييم حصتى . & 11 & \\
\hline **..104 & أستمع أكثر مما أتحدث سواء لزميلاتى أو للتلاميذ وأفكر فيما أستمع له. & IT & \multirow{5}{*}{ بتفهز } \\
\hline${ }^{\star *} . . \wedge 1$ & أستطيع فهم (فكار الآخرين . & 14 & \\
\hline **..A.1 & لا أتحيز لرأيى و اضع رأى الآخرين فى اعتبارى . & $1 \leqslant$ & \\
\hline$* * . . \vee 74$ & أقدر الصمت عندما يتحلث الآخرون بهاف الفهم وليس الرد. & 10 & \\
\hline$* * . . \vee \cdot 1$ & أققد أمثله على ما أستمع له من أفكار الاخرين. & 17 & \\
\hline$\star * * .741$ & أكسر الأطر الذهنية الجامدة والقايمة وأستبدالها بما هو حليث وجديد. & IV & \multirow{5}{*}{ بمرونة } \\
\hline$* * . \vee \vee \uparrow \wedge$ & أستطيع السيطرة على ذهنى وتوليد أفكار مختلفة تتتاسب مع الحصة . & 11 & \\
\hline **..v०१ & أقر أ البيانات قراعة متعددة ومن وجهات نظر مختلفة. & 19 & \\
\hline$*^{* *} \cdot . T \leqslant \Gamma$ & أتتلاعب بالبدائل و أتحرك ضمنها بحرية ذهنية. & r. & \\
\hline$* * . .094$ & أعتمد على حقائق متعددة بعيدة عن الطرق والأفكار القديمة. & rI & \\
\hline$* * . \vee \cdot 0$ & أتحدث عما يدور في ذهنى بدقة حينما أقوم بتطبيق الحصة. & Yr & \multirow{5}{*}{ المراءة التفكير ما } \\
\hline $\begin{array}{cc}* . V Y T \\
\end{array}$ & أبنى خرائط ذهنية تتناسب مع الحصة ومع التلاميذ. & rT & \\
\hline **..Ar. & أراقب وأتتبع مجريات التفكير التى يتم أستخدامها فى الحصة. & $r \leq$ & \\
\hline$* * .1 \cdot 9$ & أقيم الاستراتيجيات الذهنية والخطط المرتبطة بالحصة بحيث تتناسب مع مستويات التلاميذ. & ro & \\
\hline$* * . v \cdot 1$ & أخطط للاستر اتيجيات الذهنية المستخذمة في الحصة و العمل على تنفيذها وتطبيقها . & rq & \\
\hline$* * . .09$ & أ أعمل بحرفية ومهنية و إتقان فى اقل وقت وجها وتكلفة. & TV & \multirow{4}{*}{ أجل الدقاحة } \\
\hline$* * . \vee \circ 0$ & أ أختبر النتائج للتاكد من الدقة قبل التطبيق. & YA & \\
\hline **. & لدرجة الكمال في العصة تثكل أمرا مهما لى. & rq & \\
\hline${ }^{* *} \cdot . \mathrm{VT} \cdot$ & أحرص على العمل باتقان أثناء التطبيق. & $r$. & \\
\hline$* * . \wedge 1 \varepsilon$ & أعتمد على الأسئلة التى تتناسب مع تطبيق الحصة. & $\mu_{1}$ & \multirow{4}{*}{ المشكلات } \\
\hline${ }^{* *} . . \vee Y q$ & أميز بين التثشابهات والاختلافات أثناء التطبيق . & $r r$ & \\
\hline **. . . 04 & أستطيع توليد أسئلة متعددة المستوى بحيث تتناسب مع مستوى التُلاميذ. & $r r$ & \\
\hline$* * . .74 \pi$ & أسد الفجوة بين الاثشياء والربط بينها بطرح أسئلة مناسبة . & $r \varepsilon$ & \\
\hline **..V14 & أتتطم الكثير من التجارب لتطبيقها في مواقف جليدة. & ro & \multirow{5}{*}{ المواضية فى الطيق } \\
\hline${ }^{* *} . . \mathrm{VVq}$ & أرجع إلى الماضى لفحص خبراتى الإيجابية وتطبيقها فى أوقات معينه . & 47 & \\
\hline **..09 & الخبرات السابقة التى اكتسبتها هي مصدر يدعم أفكارى. & rv & \\
\hline **..VYO & أستخذم اسلوب المشابهاه لأختبار الحل المخزن لاى عذد مواجهه عقبات أثناء تطبيق الحصص. & ri & \\
\hline$\overline{* * .} . \mathrm{VVT}$ & أبنى صورة ذهنية اكثر تقدما قائمة على خبرات سابقة لدى. & rq & \\
\hline **..70Y & أفكر بكلمات و اضحة وأعبر عنها بكلمات مصحوبه بانفعالات مفهومة للتلاميذ أثناء تطبيق الحصة. & ؛. & \multirow{5}{*}{ والتوصيل } \\
\hline${ }^{* *} \cdot . \wedge \cdot 9$ & أققلل من كلمات الحشو مع التلاميذ للتعبير عن الأفكار المتعلقة بالحصة. & $\$$ & \\
\hline **..AIV & أ أعتمد على مهارات اللغة والتفكير التى تعكس المهارات الذهنية للتلاميذ. & $\sum Y$ & \\
\hline${ }^{* *} \cdot . \mathrm{VV} \leqslant$ & أربط اللغة بالتفكير بعلاقة وظيفية بطريقة سهله تناسب التلاميذ. & $\varepsilon r$ & \\
\hline **. $.7 \% 9$ & أتحدث عن الخبرات الماضية التى تم أكتسابها أثناء التطبيق بأقل قدر ممكن من الكلمات. & ؟ & \\
\hline
\end{tabular}

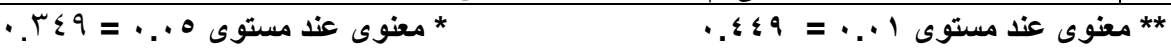


تابع جدول (ع ) معامل الاتساق الااخلى (معامل ارتباط درجة العبارة بالمجموع الكلى للعادة التى تتتمى اليها) لعبارات

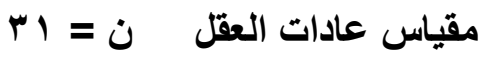

\begin{tabular}{|c|c|c|c|}
\hline معامل الاتساق & العبارات & e & العادة \\
\hline$* * . . \mathrm{V} \odot \mathrm{V}$ & أحلل الأثياء المرئية و المسمو عة والمحسوسة معاً لتكوين نظام معرفى يتناسب مع الحصة. & ¿० & \multirow{4}{*}{ باستخِ البيانات } \\
\hline **. V०r & أفكر فيى مفاتيح الذهن لاستثارة العمليات الذهنية لاى الثّلاميذ بدرجة عالبة. & 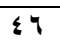 & \\
\hline$* * .74 \mathrm{~V}$ & أتعامل مع البيئة المدرسية كميدان معرفى مفتوح يطور عملياتى الذهنية. & $\varepsilon V$ & \\
\hline${ }^{* \star} \cdot . V \backslash \varepsilon$ & أحلد القتوات المعرفية الذهنية الأكثر أستخذاما والتى تتناسب مع تطبيق الحصة & $\xi \Lambda$ & \\
\hline **. & أطبق افكار جديدة غير معروفة من قبل أثثاء تطبيق الحصة . & $\leqslant 9$ & \multirow{5}{*}{ الابداع والتخيل } \\
\hline${ }^{* *} \cdot . v \leqslant r$ & أستثمر البيئة المدرسية و عناصرها بفاعلية. & 0. & \\
\hline${ }^{* *} . .779$ & أتعامل مع عدد كبير من البدائل وأظهر استعمالات جديدة للأثشياء المناسبة مع التلاميذ & 01 & \\
\hline **. $. V \leqslant 1$ & أتصور حل المشكلة التى تواجهني قبل ممارسة حلها. & Or & \\
\hline **. & أعتمد على الدوافع الذاتية لاى للوصول إلى الكمال أثناء التطبيق. & or & \\
\hline$\star * * . V \leqslant \Lambda$ & شغوفة بتقصى أسباب نجاح أو فنشل الحصة & $0 \xi$ & \multirow{3}{*}{ الاستجابة بدقة } \\
\hline$* * . \wedge 1 \%$ & أحلد ذهنيا جواتب المشكلة التى تتحداني ذهنيا والتي تو اجهني أثناء التطبيق. & 00 & \\
\hline$*^{*} \cdot . \mathrm{VVT}$ & أذهب بذهنى الى المشكلات الغامضة التى تواجهنى في الحصة و فى المدرسة لأجد لها حلا. & 04 & \\
\hline${ }^{* *} \cdot . \mathrm{TAV}$ & أنتعامل مع المخاطر الذهنية المحسوبة و أتوقع حدوثها أثناء تطبيق الحصة. & OV & \multirow{5}{*}{ الإقدام على المسئلة } \\
\hline **.. .01 & أفكر في نجاح الحصة المرتبط بالجهـ ولا أخاف من الفشل. & $0 \wedge$ & \\
\hline$* * . .70$ & أرحب بتطبيق المغامرات الذهنية مع التلاميذ . & 09 & \\
\hline$* * .79$ & أجبر نفسي ذهنيا على اقتحام المشكلة المعقدة التى تواجهنى والتى تؤدى إلى فثل الحصة . & 7. & \\
\hline$* * . .700$ & أؤمن بأن الَّخاطرة و الكفثل تساعد على معرفة الصواب وتعديل الأخطاء . & 71 & \\
\hline **.. $\mathrm{VHT}$ & أقلب الكلمات الى معانى غير مألوفة لجذب انتباة التلاميذ أثثاء التطبيق . & Th & \multirow{4}{*}{ 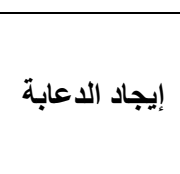 } \\
\hline **. $.94 \varepsilon$ & أخالف الواقع فى تطبيق أفكار خارجة عن موضوع الحصة . & 84 & \\
\hline${ }^{* *} \cdot . \Delta \wedge r$ & أعتمد على ألفاظ جديدة لتغيير واقع الحصة . . & $7 \varepsilon$ & \\
\hline$* * . V Y V$ & أتجنب التعصب و التحيز مع زميلاتيى ومع التلاميذ . & 70 & \\
\hline$* * . .7$ & أطوع تفكيرى لكى يتو افق مع زميلاتى حينما أفكر معهر. & 79 & \multirow{4}{*}{ 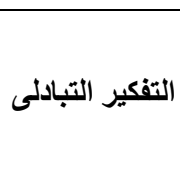 } \\
\hline${ }^{* *} \cdot . \mathrm{V} \Gamma \cdot$ & أطور تفكيزى الاجتماعى وما سيتم التعامل معه فى المدرسة. & IV & \\
\hline$* * . . V \leqslant 0$ & أجدلد مهارات الصمت الذهنى الفاعل وأتتبع مسارات تفكير الاخرين. & 71 & \\
\hline **. $.7 \leqslant \cdot$ & أتجنب الوحدة وأثشارك زميلاتى فى تفكير هم وإنجاز هم وأطور افكارهم و أفكارى. & 79 & \\
\hline **..Vץ^ & متعلمة ومحبه للاستطلاع طول الوقت لكى أجد ما هو جديد ويصلح تطبيقة & $\mathrm{ve}$ & \multirow{4}{*}{ التعلم المستمر } \\
\hline$* * . \mathrm{VIV}$ & لدائمة التغيير والتعديل وتحسين ذاتى بحيث يتوافق مع الأخرين . & $\mathrm{VI}$ & \\
\hline$* * .7 \leqslant \Lambda$ & أبحث عن التحسن والعمليات الذهنية الأكثر تقام للاستفادة منها أثناء التطبيق & VY & \\
\hline **. $.7 \vee 0$ & أفكر بطريقة مختلفة وأستكثف البدائل التي يسهل تطبيقها وتتناسب مع البيئة المدرسية . & $\mathrm{VT}$ & \\
\hline
\end{tabular}

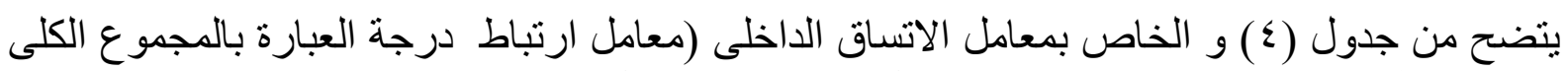

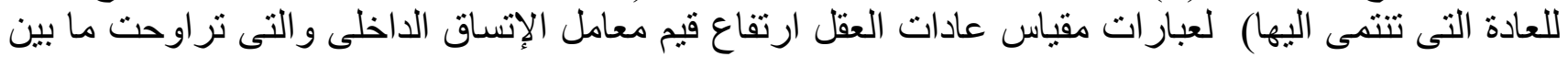

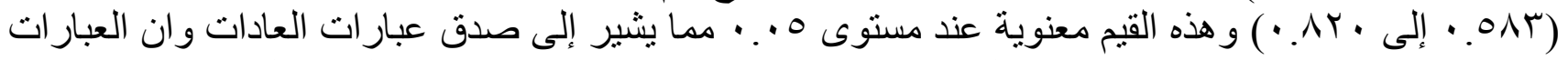

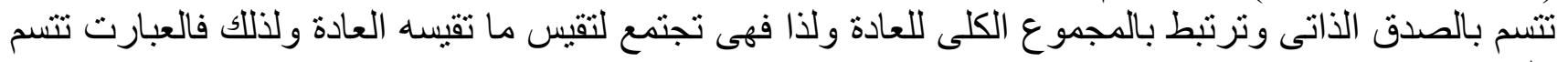

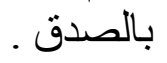


جدول (•) معامل الاتساق الداخلى (معامل ارتباط درجة العادة بالمجموع الكلى للمقياس) لعادات مقياس عادات العقل ن

\begin{tabular}{|c|c|}
\hline معامل الاتساق الداخلى & العادات \\
\hline **..74 & المثابرة \\
\hline$* * . \wedge r V$ & التحكم بالتهور \\
\hline **..V94 & الاصغاء بتفهم \\
\hline$* * .79$. & التفكير بمرونة \\
\hline **..VรO & التفكير ما وراء المعرفة \\
\hline$* * . .09$. & الكفاح من أجل الدقة \\
\hline$* * . . T \leqslant \Lambda$ & التساؤل وطرح المشكلات \\
\hline$* * .74 \mathrm{~V}$ & تطبيق المعارف الماضية فى مواقف جديدة \\
\hline$* * . \vee \vee \wedge$ & التفكير والتوصيل بوضوح ودقة \\
\hline **..VรO & جمع البيانات باستخدام جميع الحواس \\
\hline$* * .719$ & الابداع و التخيل والابتكار \\
\hline$* * .794$ & الاستجابة بدقة ودهشة \\
\hline **..VYT & الإقدام على المخاطر المسئولة \\
\hline **. . vrq & إيجاد الدعابة \\
\hline$* * .741$ & التفكير التبادلى \\
\hline **..$V Y \mu$ & التعلم المستمر \\
\hline
\end{tabular}

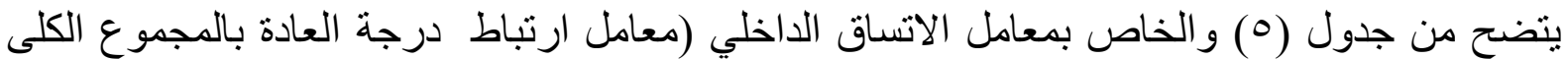

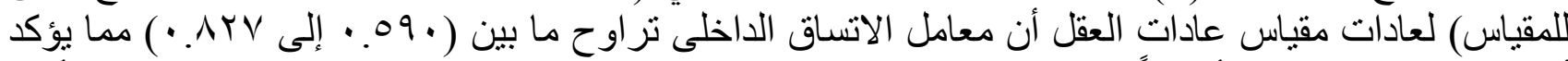

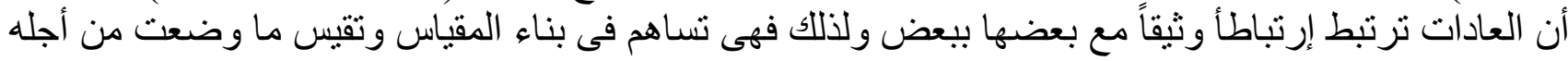

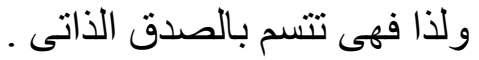




\begin{tabular}{|c|c|c|}
\hline \multicolumn{2}{|c|}{ معامل ألفا لكرونباك = = } & رونباك لعبار ات و عادات مقياس \\
\hline \multicolumn{2}{|c|}{ معامل ألفا لكرونبالك } & \multirow{2}{*}{ العادات } \\
\hline ل ل للعادات & للاعبارات & \\
\hline \multirow{16}{*}{$\because \wedge \neg \vee$} &. $\mathrm{V} 01$ & المثابرة \\
\hline & $\cdot \vee \wedge \varepsilon$ & التحكم بالتهور \\
\hline & . vor & الاصغاء بتفهم \\
\hline & $\cdot . \vee 79$ & التفكير بمرونة \\
\hline & $\cdot \cdot^{\wedge} \cdot \varepsilon$ & التفكير ما وراء المعرفة \\
\hline & $\cdot . \wedge \uparrow \wedge$ & الكفاح من أجل الدقة \\
\hline & $\cdot . \vee 71$ & التساؤل وطرح المشكلات \\
\hline & $\cdot . \mathrm{V} \bullet \wedge$ & تطبيق المعارف الماضية فى مو اقف جديدة \\
\hline & $\cdot . \wedge Y \mathrm{~T}$ & التفكير والتوصيل بوضوح ودقة \\
\hline & $\cdot . \wedge \leq \downarrow$ & جمع البيانات باستخدام جميع الحواس \\
\hline & $\because . \wedge r \mu$ & الابداع و التخيل والابتكار \\
\hline & $\cdot . \wedge \uparrow \wedge$ & الاستجابة بدقة ودهشة \\
\hline & $\cdot \wedge \leqslant \vee$ & الإقدام على المخاطر المسئولة \\
\hline &. . & إيجاد الدعابة \\
\hline & $\therefore$ Vos & التفكير التبادلى \\
\hline & $\cdot . \vee \vee 4$ & التعلم المستمر \\
\hline
\end{tabular}

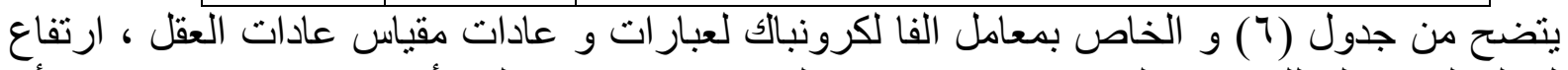

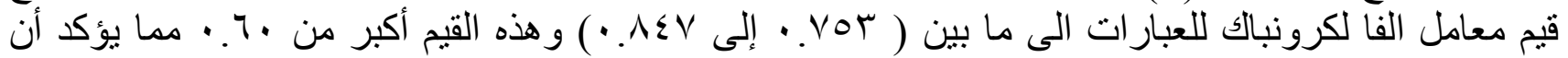

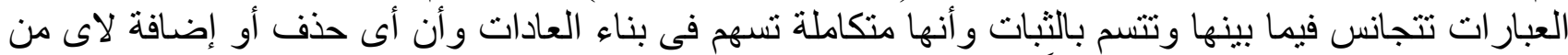

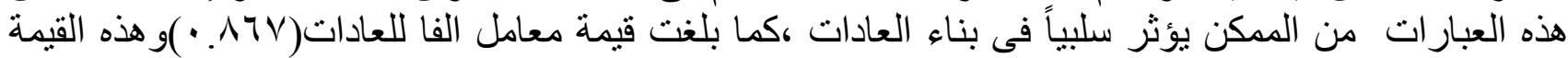

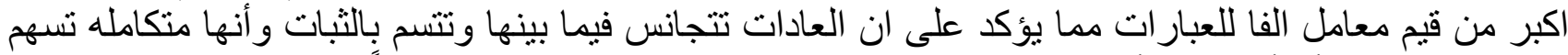

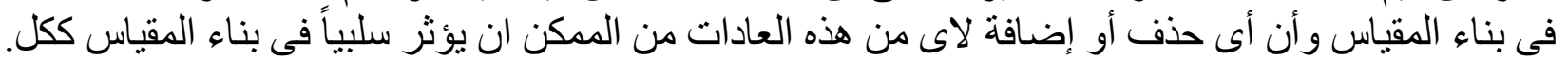

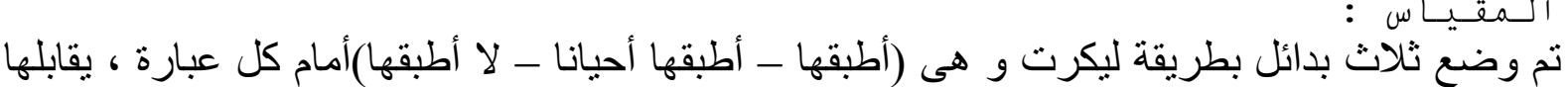

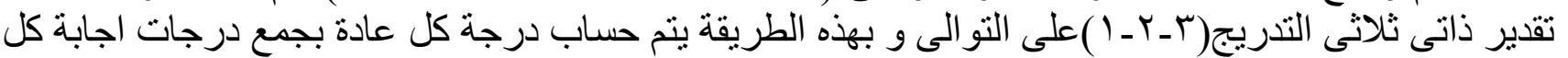
طالبة على هذه العادة، و كذللك جمع درجات إجابتها على جميع العادات لحساب درجة الحئ المقياس الكلية.

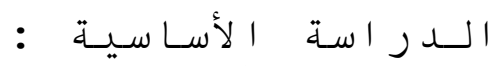

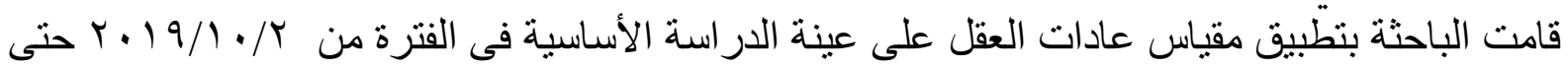

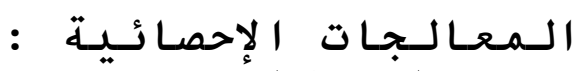

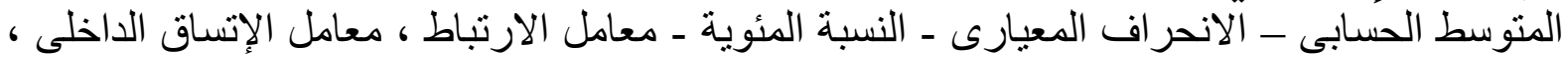
معامل ألفا لكرونباك ، اختبار (ف) الفروق - تحليل التباين (ANOVA) - اختبار (scheffe) . 


\section{- : * عرض و مـنـاقشة الـنــــائجة}

- معاملات الارتباط بين عادات مقياس عادات العقل ويين درجات التدريب الميداني:

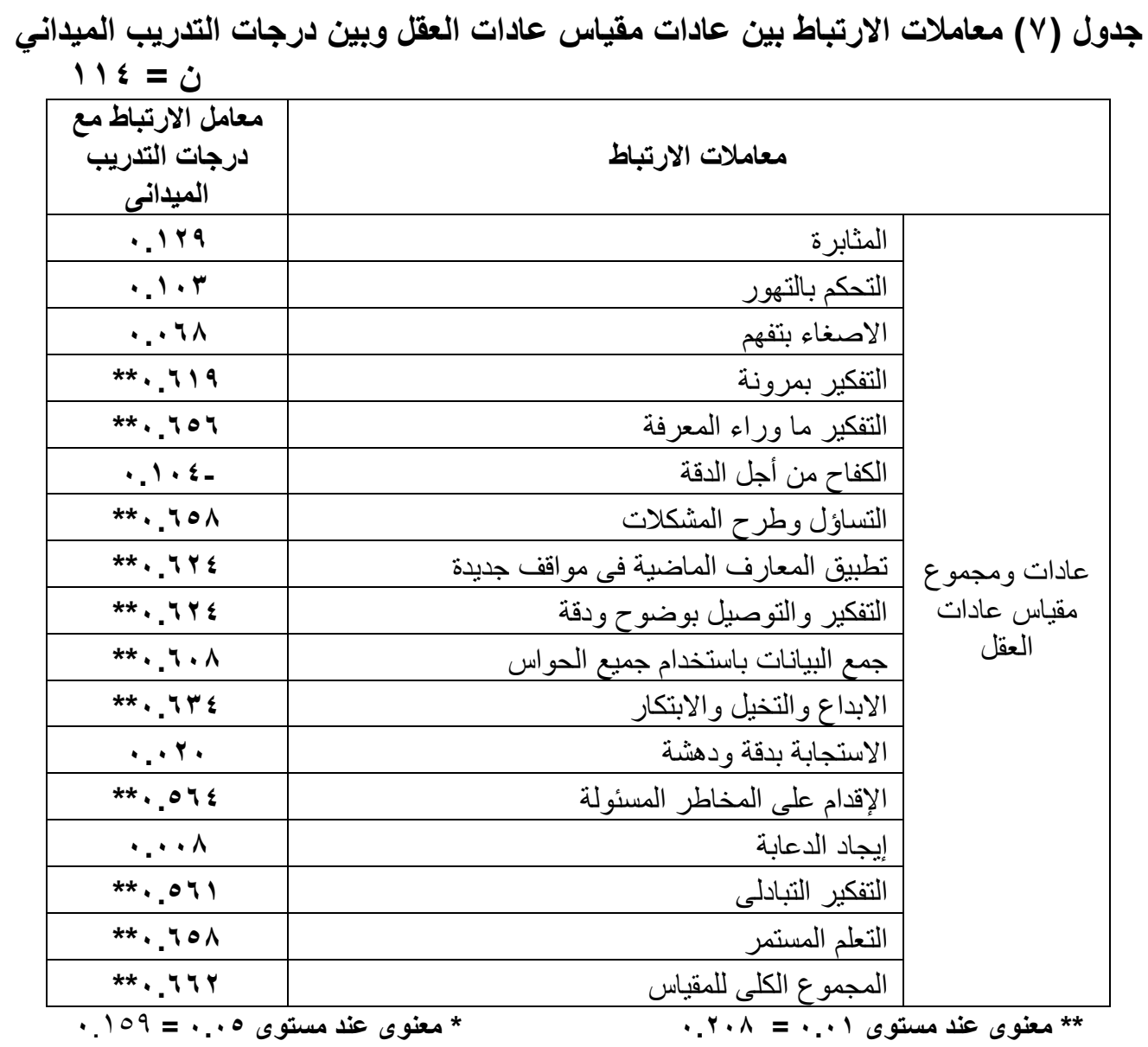

يتضح من جدول (V) و الخاص بمعاملات الارتباط (بين عادات مقياس عادات العقل وبين درجات التدريب

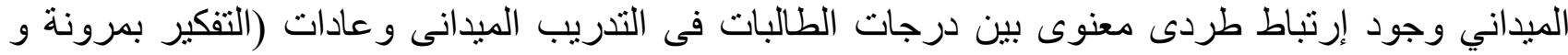

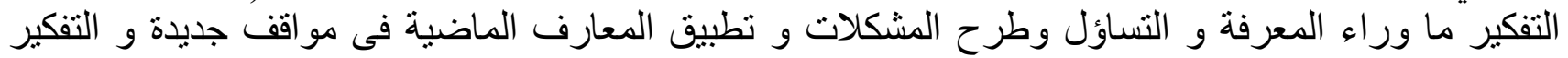

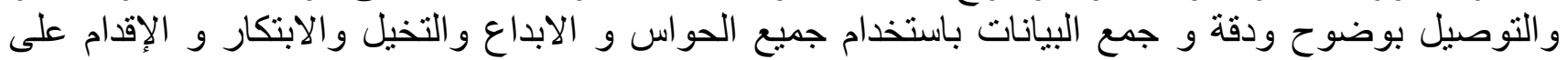

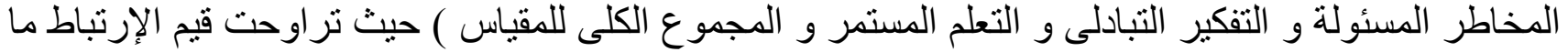

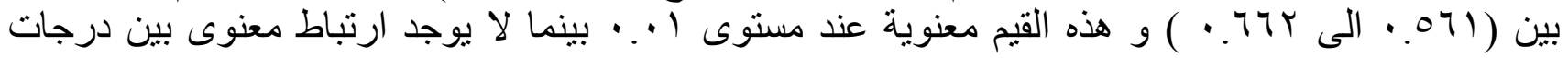

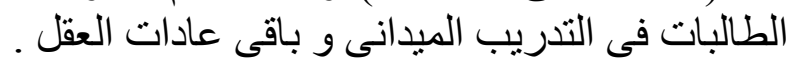

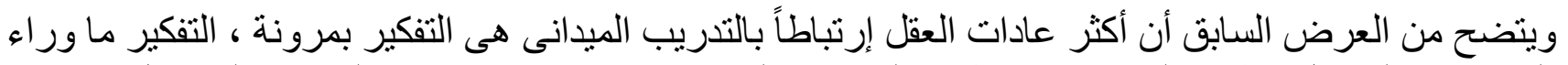

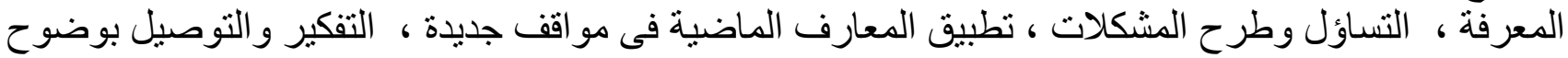

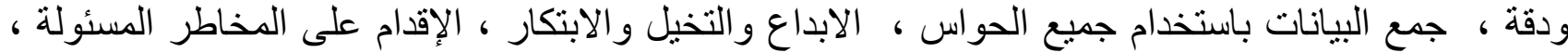

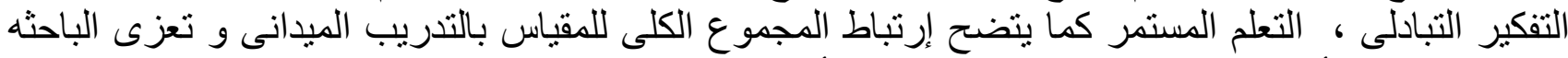

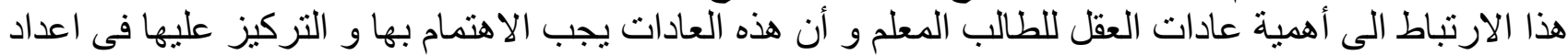

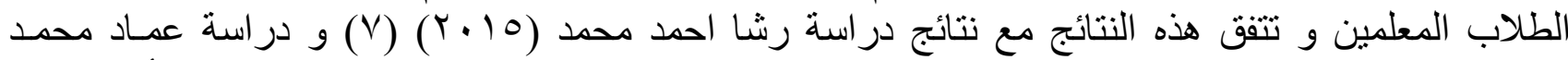

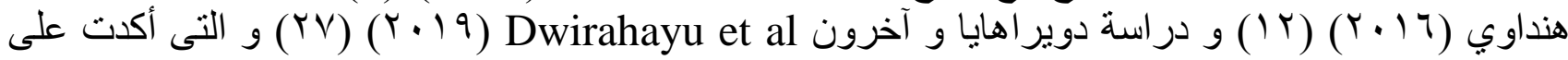

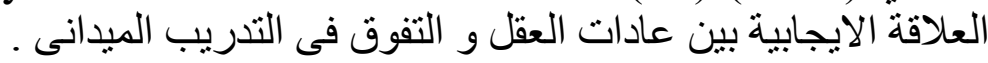




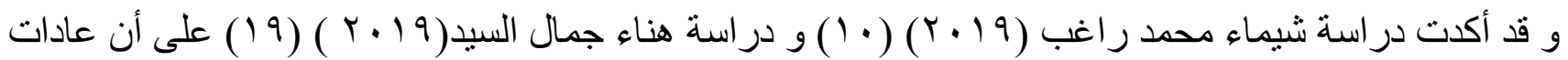

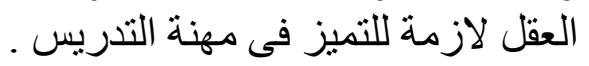

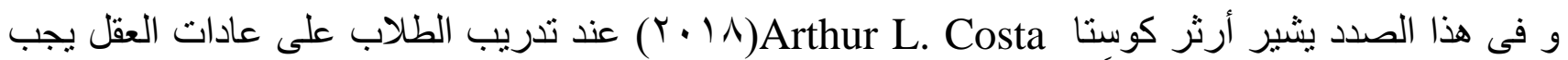

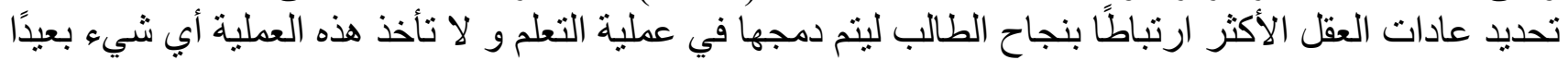

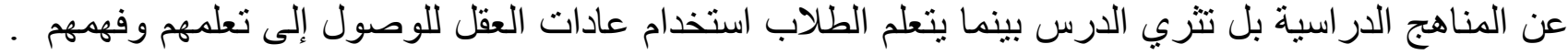

$\left(1 \wedge \varepsilon: Y^{\prime}\right)$

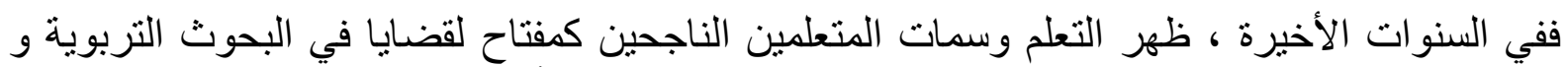

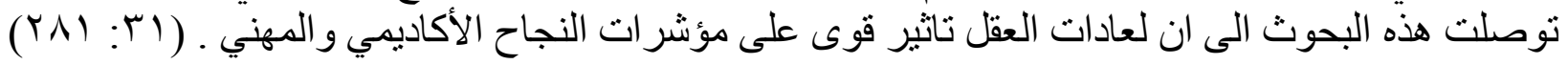

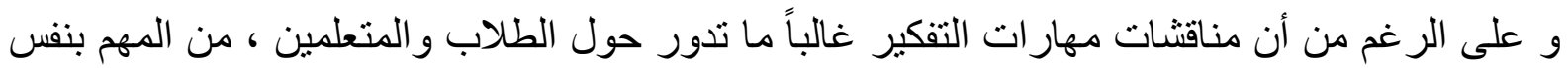

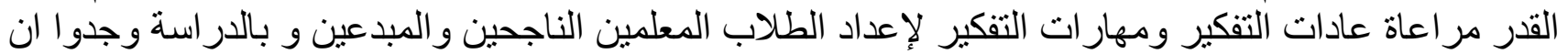

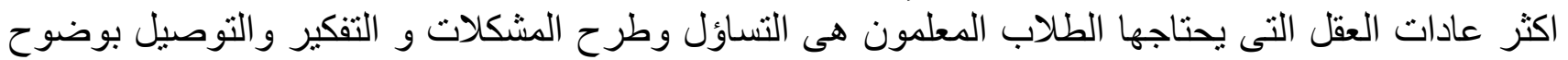

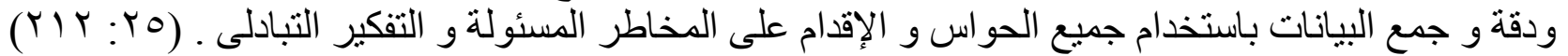

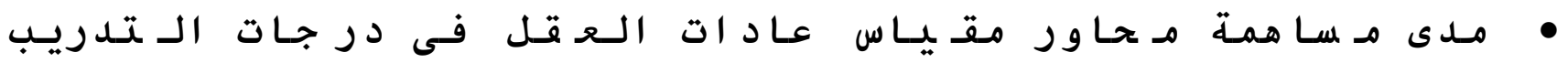

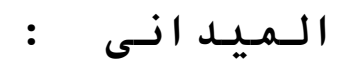

- معادلة الانحدار المتعدد بطريقة (stepwise) الحذف والاضافة :

جدول (^) دلالات معادلة الانحدار المتعدد بطريقة (stepwise) لمحاور مقياس عادات العقل في درجات التدريب ن الميذانى

\begin{tabular}{|c|c|c|c|c|c|c|c|}
\hline المعياري & قيمة & للإضمافة & الآحسارل & للمساهمية & $\begin{array}{c}\text { المساهية } \\
\text { الكنيرات } \\
\text { R2 }\end{array}$ & $\begin{array}{c}\text { الارتباط } \\
\text { معاملد } \\
\text { R }\end{array}$ & دلالات التنبؤ \\
\hline $1 .+r q$ & $\wedge 0 . \leqslant 1 \leqslant$ & $\varepsilon .7 r \varepsilon$ & $\varepsilon . V \otimes \Lambda$ & LY.Yצ & $\cdot . \leqslant r$ &. .701 & التساؤل وطرح المشكلات \\
\hline$\because A r r$ & $01 . V T 4$ & r.Y & r. .10 & Ir.ivo & $\because .00 \leq$ & $\because v \leq 0$ & التفكير بمرونة \\
\hline \multicolumn{7}{|c|}{$V \tau_{.} \cdot V r$} & قيمة القاطع \\
\hline
\end{tabular}

معادلة التنبؤ بدرجات التدريب الميدانى بمعلومية بعض محاور عادات العقل :

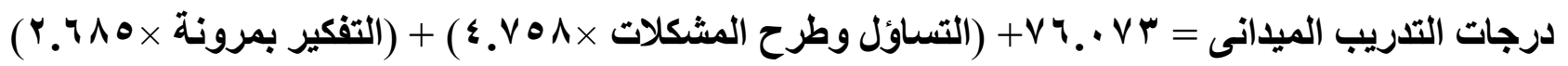
كما يتضح من جدول (^) و الخاص بدلالات الانحدار المتعدد لمحاور عـادات العقل في التفكير درجـات التدريب الميدانى أن :

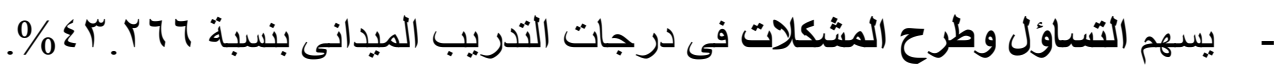

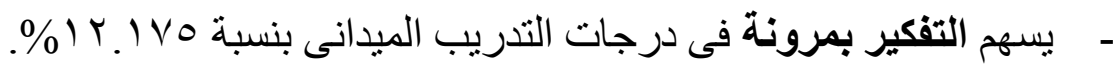
- ويسهم المحورين فى درجات التدريب الميدانى بنسبة ع.00\% كما يتضح أن جميع المتغير ات الإحصائية المؤهلة لمعادلة التتبؤ بدرجات التدريب الميدانى تؤكد فعالية المعادلة في التنبؤ . 


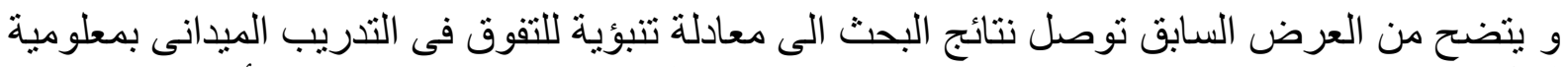

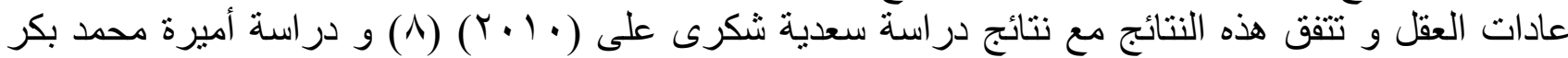

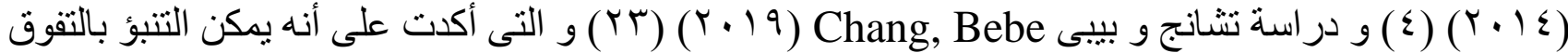
فى التدريب الميدانى اذا كان الطالب المعلم يمنلك عادات عقلية تميزه عن غيره من الطلاب .

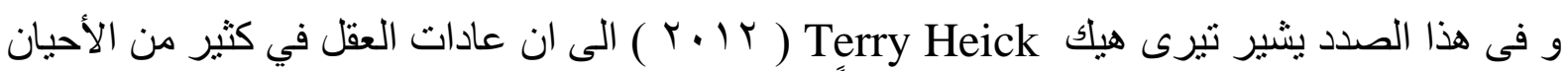

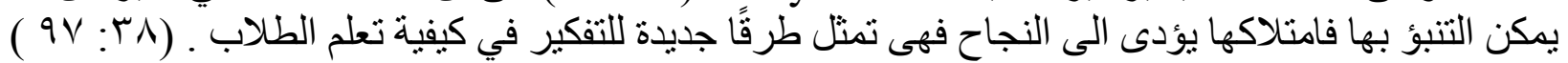

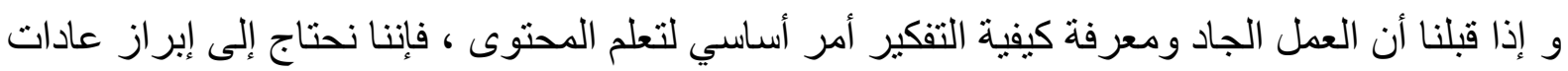

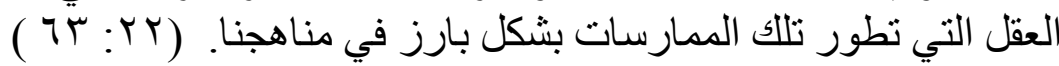

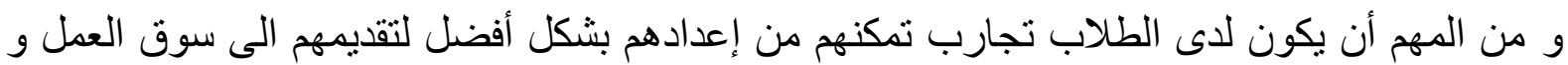

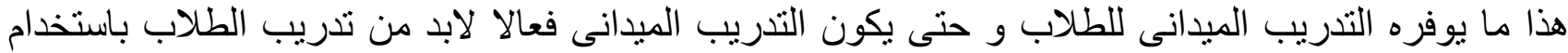

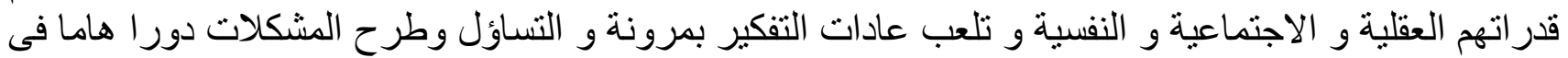

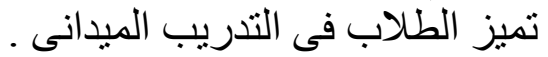

\section{$(r \cdot: r) \cdot)$}

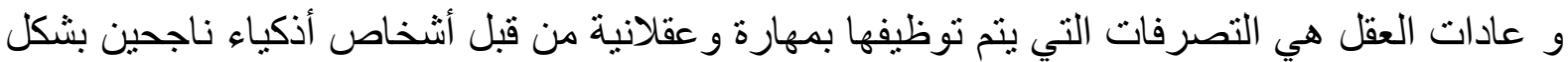

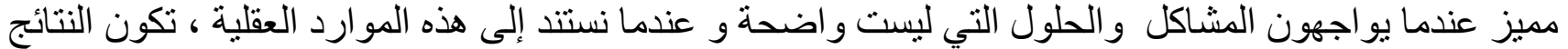

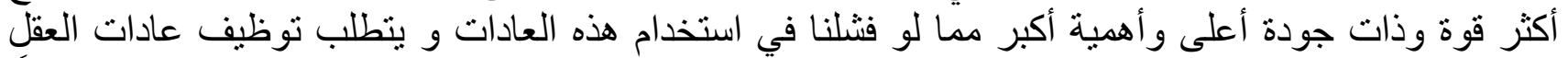

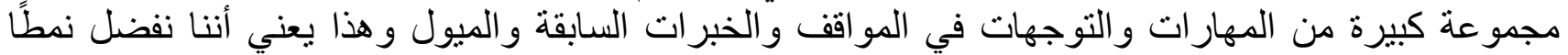
و واحدًا من التفكير على نمط آخر ، وبالتالي فهو يعني اتخاذ القرار بشأن أب عادة يجب استخدامها في أي وقت.

فى ضو ء أهداف البحث و النتائج التى تم التوصل البها استخلصت الباحتة ما يلى :

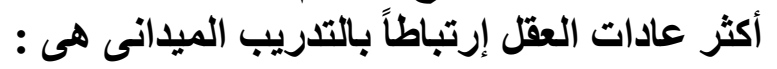

$$
\text { - - - - التفكير بمرونة . - }
$$

- م - تطبيق المعارف الماضية فى مو اقف جديدة .

- - مالتفكير و التوصيل بوضوح ودقة .

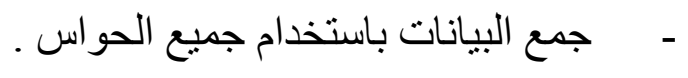

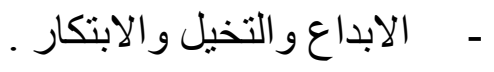

- الإقدام على المخاطر المسئولة .

-

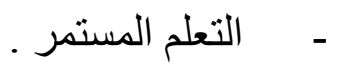


- - - - المجموع الكلى لمقياس عادات العقل .

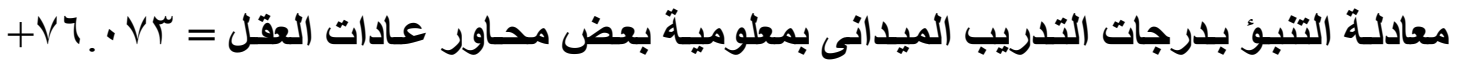

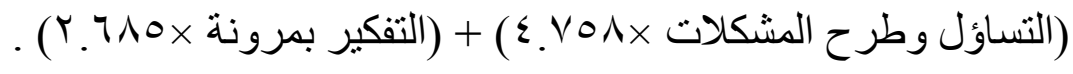

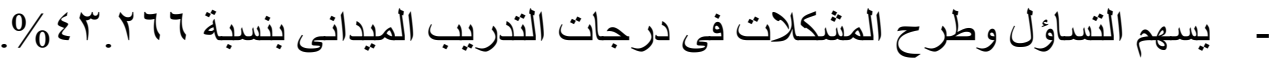

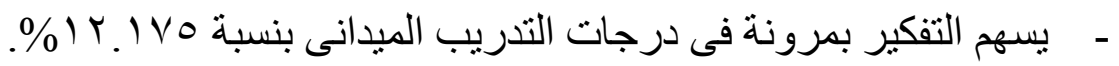
- ويسهم المحورين فى درجات التدريب الميدانى بنسبة ؛.00\%

إعدا المناهج و المقرر ات التى تؤهل الطالبة للعمل بمجال التدريس فى ضوء عادات العقل . إعداد بر امج تدريبية تنمي عادات العقل لدى الطالبات .

ضرورة التعرف على عادات العقل في المر احل التعليمية المختلفة وممارستها.

تدريب الطالبات على غرس عادات العقل لدى تلاميذهن لتكون حلاً لكثير من المشكلات التي تو اج8هم.

$$
\text { إتاحة الفرصة أمام الطالبات للتدريب الكافي على مهار ات عادات العقل. }
$$
• تطبيق عادات العقل عند إختبار الطالبات فى شعبة تعليم . 


\section{ق قــانـــة الـمـر اجـع \\ أولا : : الـمـر اجع الـعـربـيـة :}

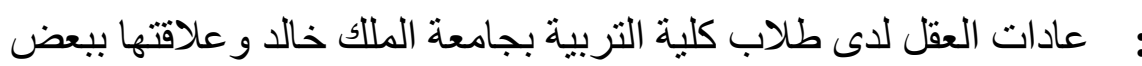

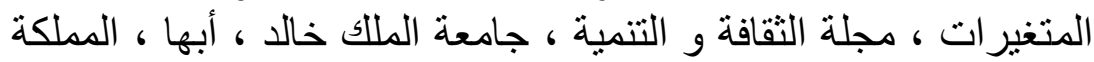

( ) إبراهيم أحمد إبراهيم

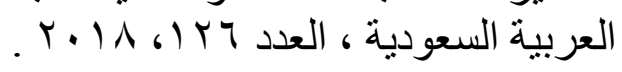

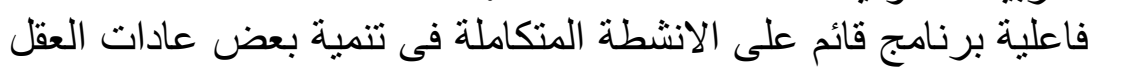

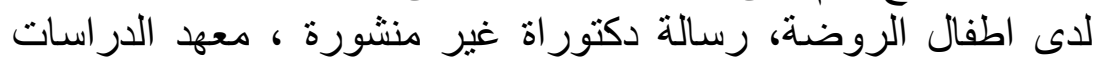

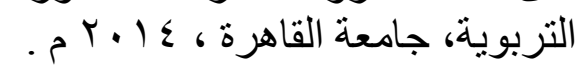

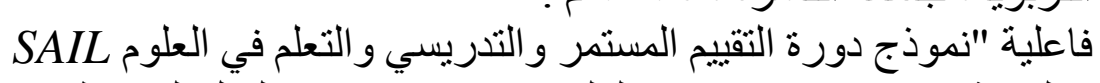

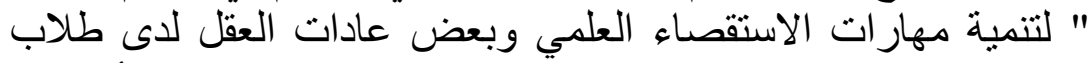

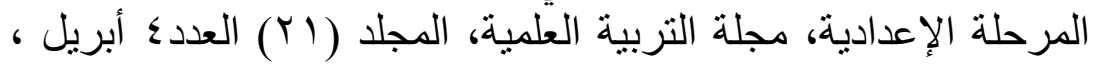
الأبكاء : الأكاء الأخلاقى وبعض عادات العقل لادى مرتفعى ومنخفضى الكفاءة

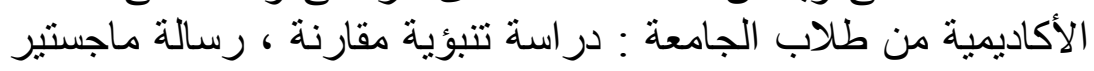

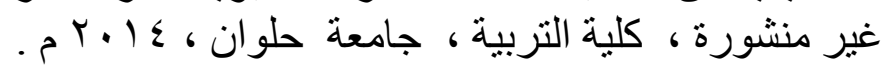

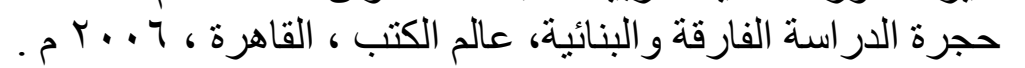

عادات العقل و علاقتها بالذكاءات المتعددة لاى طلاب السنة التحضيرية

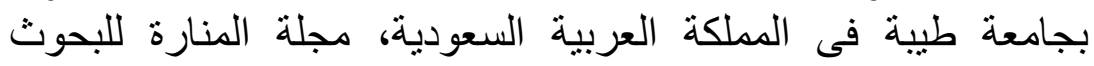

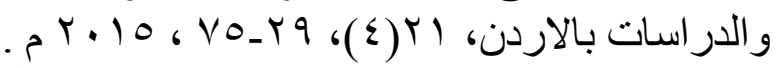

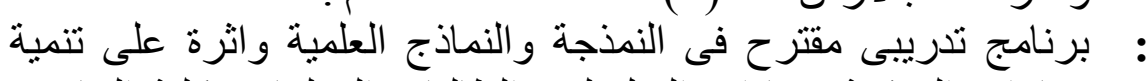

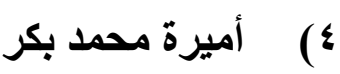

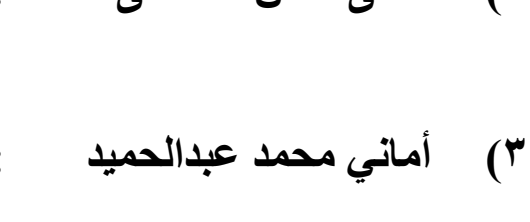

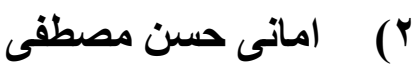

r 


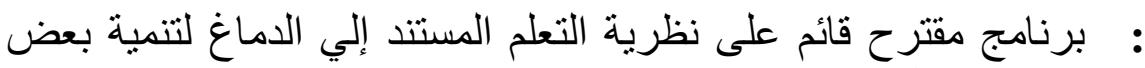

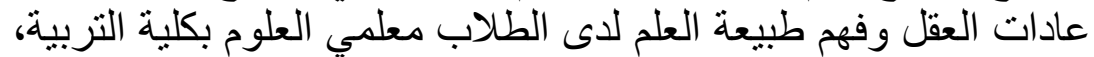

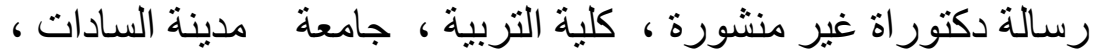
.

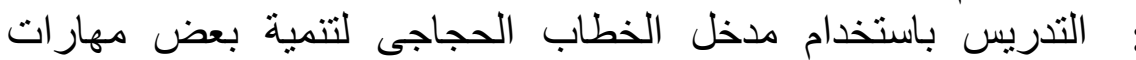
الدر اسة و عادات العقل لدى الطلبة المعلمة شعبة التاريخ، مجلة الجئة الجمعية

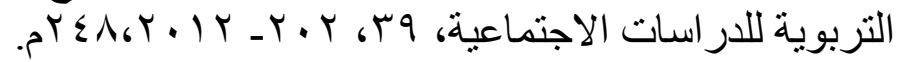

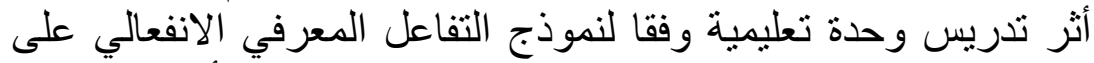

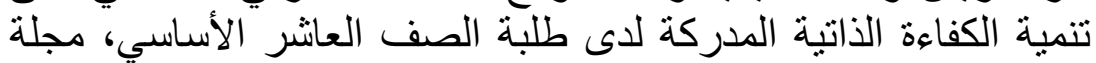

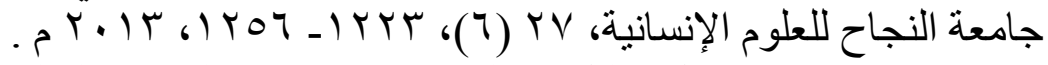
تتوع التدريس في الفصل (دليل المعلم) لتحسين طرق التعليم و التعلم في

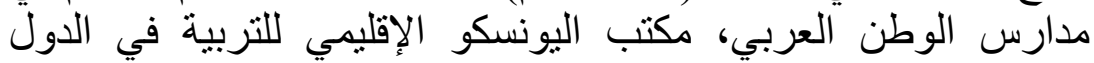

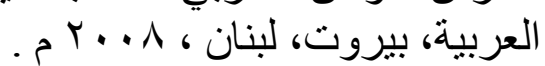

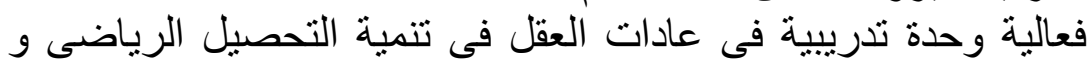

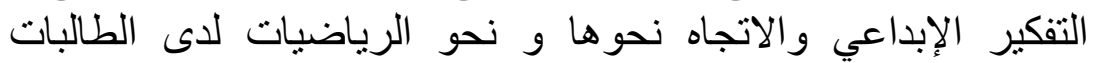

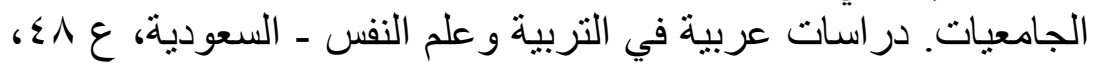

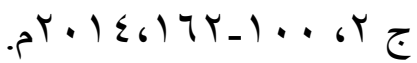

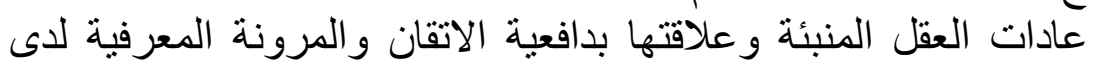

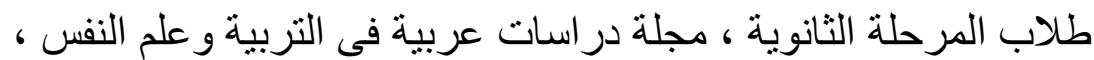

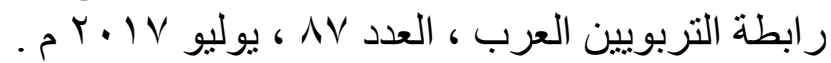

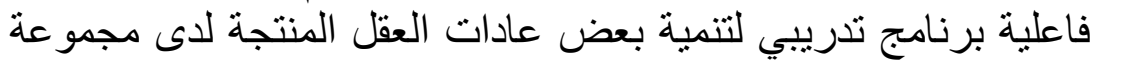

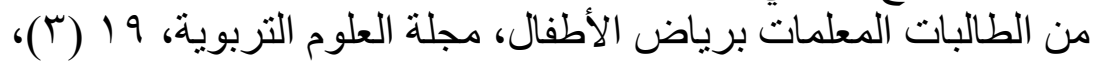

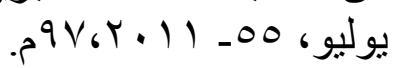

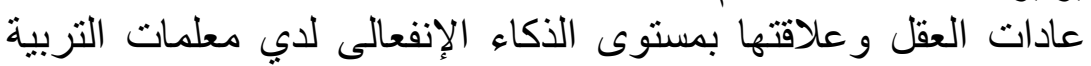

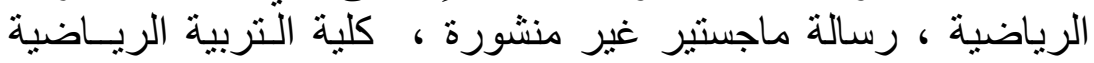

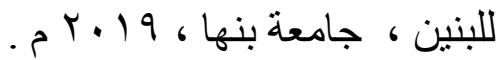

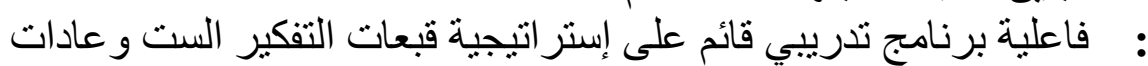

\section{ع أ) : فراس طلافحة ، الحمران محمد} 10

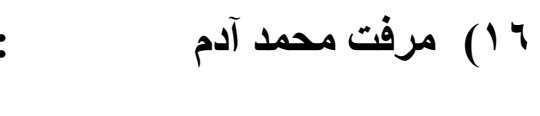
: مروة صلاح ابراهيم (IV : 11 ) : منار عبدالحميد السواح (19 ) هناء جمال السبد و الاء مصطقى محمد

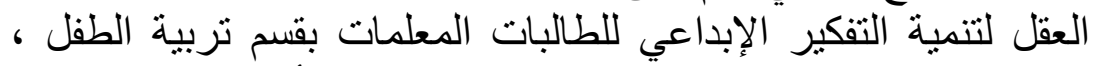

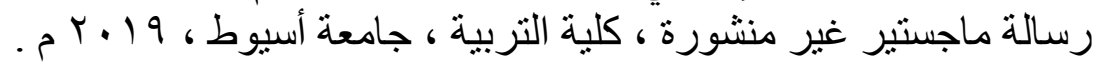

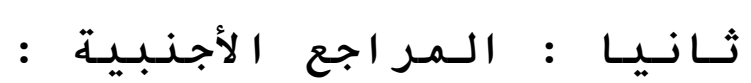

21 - Arthur L. Costa : 6 tips for leading schools with 'Habits of Mind' in mind, ASCD , JANUARY 2, 2018 .

22 - Arum, R., and : Academically Adrift: Limited Learning on College J. Roska Campuses. Chicago: University of Chicago Press, 2011.

23 - Chang, Bebe : "From Research Aesthetics to Habits of Mind: Student Publishing as a Core Competency " (2019). Staff Presentations, Proceedings, Lectures, and Symposia. 30.

24 - Costa, A.\& : Habits of mind in the curriculum. Available from:' Kallick www.mindfulbvdesign.com [Accessed: 17 September , 2013.

25 - Danah : The seven transdisciplinary habits of mind of creative teachers: An Henriksen exploratory study of award winning teachers, Thinking Skills and Creativity, Volume 22, December 2016, Pages 212-232 .

26 - Deneen, $\mathbf{J} \quad$ : Schools that succeed, Students who achieve: Profiles of programs 
helping all students to learn. Maryland: Rowman \& Littlefield Publishers. Inc,2010.

27 - Dwirahayu et al : Corresponding Habits of Mind and Mathematical Ability , Journal of Physics: Conference Series, Volume 895, conference 1, 2019.

28 - Ellen J : Using the science teaching standards to nature habits of the mind in the middle school students, Master of education, The School of Education, Pacific Lutheran University, 2001.

29 - Fenderson, $\mathbf{S} \quad$ : Instruction, perceptio, and Reflection: Transforming Beginning Teachers' Habit of Mind", Proquest LLC, Ed. D. Dissertation, University of San Francisca, 2010 .

30 - Ioannis

: Using mobile puzzles to exhibit certain algebraic habits of mind and demonstrate symbol-sense in primary school students, The Journal of Mathematical Behavior , Volume 53, March 2019, Pages 210-227.

31 - John Campbell : Theorising Habits of Mind as a Framework for Learning, Central Queensland University, aare, 2006.

32 - Lepage, P.\& : Computer Conferencing and the Development of Habits of Mind Robinson Associated will Effective Teacher Education", Journal of Interactive learning Research, 16(4), 369-393, 2005.

33 - Lisette et al

: Teachers' role in stimulating students' inquiry habit of mind, Teaching and Teacher Education , Volume 86, November 2019, 102894.

34 - Mark et al $\quad$ : Developing Mathematical Habits of Mind, Mathematics Teaching in the Middle School, 15 (9), 505 - 509,2010.

35 - Steinkuehler, \& : Scientific Habits of Mind in Virtual Worlds, Journal of Science Duncan Education and Technology, 17(6), 530-543, 2008.

36 - Suad Alhamlan : Using Habits of Mind to Improve Student ${ }^{\text {ee }}$ thinking, Higher et al Education Studies; Vol. 8, No. 1; 2018 ISSN 1925-4741 E-ISSN 1925-475X Published by Canadian Center of Science and Education, 2018.

37 - Teach Thought : What Are The Habits Of Mind?, TeachThought is an organization Staff dedicated to innovation in education through the growth of outstanding teachers, August 4, 2017.

38 - Terry Heick : Integrating the 16 Habits of Mind, CRITICAL THINKING , GEORGE LUCAS EDUCATIONAL FOUNDATION, edutopia , October 19, 2012.

39 - Zeidler, et al : Advancing reflective judgment through Socioscientific Issues. Journal of Research in Science Teaching, 46(7), pp.74-101,2009. 


\section{الدمـلخدص}

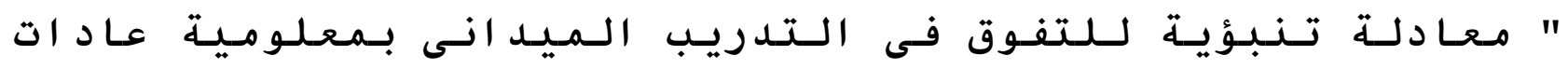

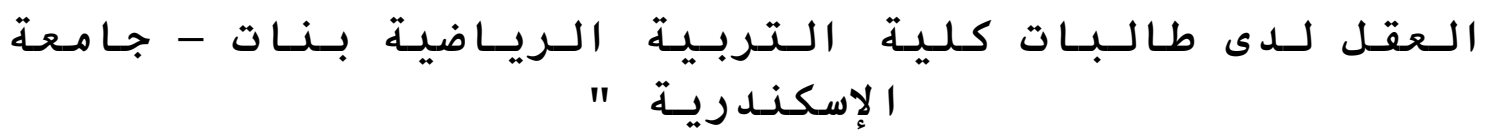

يهدف البحث الى إلى التوصل الى معادلة تتبؤية للتقوق فى التدريب الميدانى بمعلومية عادات العقل و

ذللك من خلال التعرف على عادات العقل المساهمة فى التقوق فى التذريب المبدانى و وضع معادلة تنبوئية للتفوق فى التدريب الميدانى بمعلومية عادات العقل، إستخدمت الباحثة المنهج الوصفى بالأسلوب المسحى ، تم اختيار عينة البحث بالطريقة العدية و تكونت من ع (1 طالبة مقسمين الى مستويات معيارية بناء على الدرجات الى مستوى عالى و عددهن rr طالبة و المستوى المتوسط و عددهن OV طالبة و المستوى المنخفض و عددهن هץ طالبة ، تم استخدام مقياس عادات العقل كأداة لجمع البيانات ، و توصلت نتائج الدراسة الى أن أكثر عادات العقل المساهمة فى تفوق الطالبات فى التدريب الميدانى هى التفكير بمرونة و التفكير ما وراء المعرفة و التساؤل وطرح المشكلات و تطبيق المعارف الماضية فى مواقف جديدة و التفكير والتوصيل بوضوح ودقة و جمع البيانات باستخدام جميع الحواس و الابداع والتخيل والابتكار و الإقدام على المخاطر المسئولة و التفكير التبادلى و التعلم المستمر و نم التوصل الى معادلة يمكن من خلالها التتبؤ بدرجات الطالبات فى التذريب • الميدانى 


\section{Abstract \\ ${ }^{6}$ A predictive equation for superiority in the field training with the knowledge of mind habits among the female students of the Faculty of Physical Education for Girls - Alexandria University"}

The research aims at reaching a predictive equation for superiority in the field training with the knowledge of mind habits that contribute to the superiority in the field training and creating a predictive equation for the superiority in the field training with the knowledge of mind habits. The researcher used the descriptive method using the survey method, and the research sample was purposively selected and consisted of 114 female students divided into standard levels according to the grades to a high level each consisted of 32 students and the average level was 57 female students and the low level was 25 female students. The mind habits scale was used as a data collection tool. The results showed that the most mind habits that contribute to the superiority of female students in the field training are: flexible thinking, thinking beyond knowledge, wandering, finding problems, applying past knowledge in new situations, thinking and communicating clearly and precisely, collecting data using all the senses, creativity, imagination, innovation, taking responsible risks, mutual thinking, and continuous learning, finally an equation was reached by which the students' grades can be predicted in the field training. 